\title{
Gravity wave spectra, directions and wave interactions: Global MLT-MFR network
}

\author{
Alan H. Manson ${ }^{1}$, Chris E. Meek ${ }^{1}$, Chris Hall², Wayne K. Hocking ${ }^{3}$, John MacDougall ${ }^{3}$, Steven Franke ${ }^{4}$, Kiyoshi Igarashi ${ }^{5}$, \\ Dennis Riggin ${ }^{6}$, David C. Fritts ${ }^{7}$, and Robert A. Vincent ${ }^{8}$ \\ ${ }^{1}$ Institute of Space and Atmospheric Studies, University of Saskatchewan, Canada \\ ${ }^{2}$ Auroral Observatory, University of Troms $\phi$, Norway \\ ${ }^{3}$ Dept. of Physics and Astronomy, University of Western Ontario, Canada \\ ${ }^{4}$ Space Science and Remote Sensing Laboratory, University of Illinois, U.S.A. \\ ${ }^{5}$ Upper Atmosphere Section, Communications Research Laboratory, Tokyo, Japan \\ ${ }^{6}$ Colorado Research Associates, Boulder, U.S.A. \\ ${ }^{7}$ Dept. of Electrical and Computer Engineering, University of Colorado, U.S.A. \\ ${ }^{8}$ Dept. of Physics and Mathematical Physics, University of Adelaide, Australia
}

(Received August 7, 1998; Revised July 15, 1999; Accepted July 15, 1999)

\begin{abstract}
Observations of winds and gravity waves (GW) by MF radars from the Arctic to the Equator are used to provide frequency spectra and spectral variances of horizontal motions, and information on the predominant azimuthal directions of propagation for the waves. The years used are mainly 1993/4; the height layer 76-88 km; and the GW bands $10100 \mathrm{~min}$. and 1-6 hrs. The high/mid-latitude locations of Troms $\varnothing$, Saskatoon, London/Urbana, Yamagawa, generally demonstrate similar behaviour: the monthly spectra have slopes near $-5 / 3$ in winter months, but smaller (absolute) slopes at higher frequencies $(<2 \mathrm{hrs}$.) in summer. Corresponding to this, the spectral densities (10-100 min.) are larger for conditions of higher mean background windspeed - this is related by means of a new correlation-vector technique to GW propagating anti-parallel to the mean zonal winds, and the closure of the solstitial mesospheric jets. Also consistent with this, the sizes and orientations of perturbation ovals (fitted to the wind variations), demonstrate strong semi-annual-oscillations (SAO), and generally similar monthly and latitudinal directions. This suggests strong control, especially of the high-frequency GW band, by the dominant zonal windstructures of the mesosphere. In contrast the low-latitude locations of Hawaii and Christmas Island demonstrate uniquely different behaviours, with indications of significant inter-annual variability. The frequency spectra for all months tend to have smaller slopes at higher frequencies. Also the dependence of spectral density in both GW bands, upon background wind speed, is negative rather than positive, and is shown to be generally consistent with GW propagating parallel to the mean-global winds. This is consistent with weaker vertical shears in the zonal winds (76-88 km), and lower GW momentum depositions. The perturbation ovals reveal much weaker SAO, and more variable orientations, consistent with more dependency upon GW sources, and less control by the mean winds of the mesosphere.
\end{abstract}

\section{Introduction}

Medium Frequency Radars (MFR) are particularly useful for particular types of Gravity Wave studies. They have a large height coverage 60/80-100 km (day/night), close to continuous data acquisition with time due to the ubiquitous nature of the radar scatterers, and good sampling rates (2$5 \mathrm{~min}$.). The disadvantages are mainly those of limited vertical height resolution (sampling is typically $2-3 \mathrm{~km}$ with $\sim 3 \mathrm{~km}$ pulses). The most-used data for GW studies are the variances of the horizontal wind, whether they be obtained by a filter of some type, or spectral analysis followed by appropriate band-pass filtering.

The variances for high and low frequency GW bands (e.g. $10-100$ min., $1-6$ hrs.) and for heights of $60-100 \mathrm{~km}$ over 12 months, when used to form climatologies with contour

Copy right $(\mathrm{C})$ The Society of Geomagnetism and Earth, Planetary and Space Sciences (SGEPSS); The Seismological Society of Japan; The Volcanological Society of Japan; The Geodetic Society of Japan; The Japanese Society for Planetary Sciences. plots, have been a very useful product (e.g. Meek et al., 1985; Vincent and Fritts, 1987; Manson and Meek, 1993; Thorsen and Franke, 1998). The fitting of ellipses, or more properly "ovals", to the wind perturbations, has also been used to determine the predominant directions of GW propagation or activity (Manson and Meek, 1993; Gavrilov et al., 1995). Variants of this approach have used the Stoke's Parameters (Vincent and Fritts, 1987). The use of winds data for the higher frequency band (10 min.-3 hrs.), from a multiple bi-static system called GRAVNET, have also been used to provide seasonal $\mathrm{GW}$ intrinsic characteristics for periods from $10 \mathrm{~min}$. to $60 \mathrm{~min}$. (Manson and Meek, 1988). These $\mathrm{GW}$ characteristics compare very well with recent data from a scanning optical system (Wiens et al., 1997). These observations have indicated the value of MFR data when appropriately analyzed.

These climatologies and related studies have considerable value in defining the GW characteristics at a few, mainly mid-latitude, locations. It is now well known that GW play 
a dominant role in determining the dynamical and physical state of the atmosphere, especially at mesospheric heights (Fritts, 1989). All general circulation models (GCM) must incorporate $\mathrm{GW}$ effects in some reasonably realistic fashion, before their global wind and temperature fields are in any way realistic (e.g. Medvedev et al., 1998). However there must be useful global observations of these GW to use as input to the GCMs, either directly or for use as a diagnostic against the characteristics of the model. Given that, there is remarkably little available to us on global GW characteristics, and often comparisons have to be made which include observational systems of different sensitivity to various parts of the GW spectrum (e.g. Gardner and Taylor, 1998; Manson et al., 1998a). Some studies exist using MFR and MST radars: for example Nakamara et al. (1996) have utilized Saskatoon $\left(52^{\circ} \mathrm{N}\right)$, Kyoto $\left(35^{\circ} \mathrm{N}\right)$ and Adelaide $\left(35^{\circ} \mathrm{S}\right)$ data $(15 \mathrm{~min} .-$ $6 \mathrm{hrs}$.) to show generally the presence of an SAO (semiannual-oscillation) in GW intensities, with larger intensities at lower latitudes. This study followed a very detailed comparison of the MFR and MST (MU) data, including the high frequency GW band (Nakamura et al., 1993).

Recently a study has been completed at Saskatoon (Manson et al., 1997, hereafter MMZ) which has extended the themes and scope of GW studies. Three MFR's, located in a $500 \mathrm{~km}$ triangle in the Canadian prairies (Saskatoon $52^{\circ} \mathrm{N}$, Sylvan Lake $52^{\circ} \mathrm{N}$, Robsart $49^{\circ} \mathrm{N}$ ), plus the Troms $\varnothing$ MFR, were used. Frequency spectra were prepared (10 min.$10.7 \mathrm{hrs}$.) and their monthly characteristics (intensities and slopes) were compared: strong universality of slope-change throughout the year was noted, and Doppler-shifting phenomena were clearly identified. The behaviour of the spectra under different background-wind conditions was shown to be very consistent with the spectral changes first noted by Fritts and Wang (1991), who used MST radar data from Alaska. There is considerable discussion of these data and related GW in the MMZ paper. The orientations of the "perturbation ovals" demonstrated significant monthly changes with location: these were shown to be due to Doppler effects again, especially at higher frequencies (10-100 min.), but also to source changes (direction and magnitude).

The study by MMZ was largely a regional one. In the present paper we use the same methodologies to investigate the particular highlights found in the Canadian Prairies over a large range of latitudes $\left(70-2^{\circ} \mathrm{N}\right)$ using 7 MFR systems of effectively identical design. In Section 2 the data analyses of MMZ are simply summarized; Section 3 focuses on spectra; and in Section 4 the Doppler-shifting phenomena are explored; Section 5 presents "perturbation ovals" and Section 6 provides contour plots of GW variances and of mean wind speeds. The radars are at Troms $\varnothing\left(70^{\circ} \mathrm{N}\right)$, Saskatoon $\left(52^{\circ} \mathrm{N}\right)$, London $\left(43^{\circ} \mathrm{N}\right)$, Urbana $\left(40^{\circ} \mathrm{N}\right)$, Yamagawa $\left(32^{\circ} \mathrm{N}\right)$, Hawaii $\left(22^{\circ} \mathrm{N}\right)$ and Christmas Island $\left(2^{\circ} \mathrm{N}\right)$. Apart from Troms $\varnothing$ (Norway), these locations are all in the North AmericanPacific longitudinal quadrant. There is a brief summary.

\section{MF Radars and Data Analysis}

The initial analysis applied to the radar data is the fullcorrelation analysis (FCA) for spatial antenna systems. The variant developed by Meek (1980) is used for several stations (Troms $\varnothing$ to Urbana), partly due to its usefulness in dealing with correlograms that are noisier or multi-peaked; while a more classical Brigg's method is used at the other stations (e.g. Isler and Fritts, 1996) at Yamagawa, Hawaii and Christmas Island. Comparisons have shown that no significant differences exist between these methods (Thayaparan et al., 1995). The radars provide samples of wind every 2 or $3 \mathrm{~km}$ (circa $70-100 \mathrm{~km}$ ) and 2 or $5 \mathrm{~min}$. on a continuous basis.

There have also been several comparisons between radar, optical and satellite systems in recent years. Such studies are complex and require considerations of differences in spatial and temporal averaging and physical processes e.g. Cervera and Reid (1995), Manson et al. (1996), Meek et al. (1997). The latter contains comparisons between optical (FPI) and satellite systems (UARS-HRDI). A general conclusion appears to be that MFRs at several locations e.g. Troms $\varnothing$, Saskatoon, Hawaii, produce wind speeds lower than other radars and/or HRDI: the bias is typically $20-40 \%$. The effect appears to be more serious above $90 \mathrm{~km}$. However, wind directions, and related phase measurements such as those in tidal studies, show no similar bias. The speed bias should be remembered when site comparisons are made later in this paper; however, we note that the data shown here are primarily from lower heights $(76-88 \mathrm{~km})$ where the effect is even smaller.

The spectral analysis method used on the horizontal winds is the classical periodogram method for evenly spaced data (linear interpolation was used to fill the gaps in sequences). The choice of this approach has been well described elsewhere (Zhan et al., 1996) where its sensitivity to gaps was tested using synthetic data of known spectral slope. The periodograms have been shown to be largely insensitive to gaps occurring in typical data from the MF radars: the gaps are most commonly 1 or 2 ( $5 \mathrm{~min}$. or $2 \mathrm{~min}$.) points; gap percentages in 10.7-hr. sequences (128 points) are most commonly 20-30\%; and sequences with more than 50\% gaps are normally excluded. These will be used in Section 3 for the layer $76-88 \mathrm{~km}$. Integration of the frequency spectra was also carried out from 10-100 min., and 1-6 hrs. at each site, for seasonal comparisons of wind fluctuations (or gravity wave spectral variances) between locations. These are used in Sections 4 and 6.

We also apply the "correlation vectors" method. This was developed for the Lidar-MFR comparisons/collaborations which were part of ANLC-93 (Manson et al., 1998a), in a successful effort to obtain GW propagation directions. Simply, the hourly mean winds over 10 -d intervals are correlated with their standard deviations: the latter were shown by Gavrilov et al. (1995) to be a band pass filter for GW variances of 10-150 min. These correlations are calculated for all directions, $0-360^{\circ}$ East of North. i.e. the mean wind for each direction is correlated against the s.d. of the mean in each of these directions. If there is a preferred direction (dominant correlation magnitude) for GW propagation at a given height over the time interval analyzed, and if the waves are saturated, a simple model can be used to infer the GW phase-speed directions. Note that this is the direction which exhibits most significant control of GW variance by the mean winds. As the $\mathrm{GW}$ perturbations $\left(\mathrm{v}^{\prime}\right)$ for saturation vary as intrinsic phase speed (c-v), these perturbations should be pos- 
itively correlated with the component of wind in a direction anti-parallel to the phase speed (or a phase speed less than the wind). In this way, the preferred directions for phase propagation can be found by selecting the directions with highest correlation and adding 180 degrees. It should be noted that this discussion is related to the well known argument for GW saturation, momentum deposition, and reversal of the solstitial means winds (e.g. Fritts, 1989). As such it should demonstrate situations where these assumptions apply well.

As well as being useful for ANLC-93, the method was also used in a study of GW intensities, and their modulation by tides and PW (Manson et al., 1998b). In this latter, 10-d correlation vectors were plotted for a year, at heights from 76-94 km (every $3 \mathrm{~km}$ ). The inferred general zonal directions for the GW were eastward in summer, and westward in winter, the expected and required directions for GW which are depositing momentum and reversing the stratospheremesosphere solstitial jets. More specifically, the GW propagation directions inferred from the "correlation vectors" in these two Manson et al. (1998a, b) papers were consistent with other independent methods. In the former (1998a) paper, lidar and radar-phase methods also suggested GW propagation into the NE quadrant. In the latter (1998b) the phases of the GW-modulations by the tides/2d wave clearly inferred GW propagation into the NE quadrant (summer), which was the direction shown by a significant 'cluster' of vectors (their figure 11). These are useful indicators of the method's validity, or perhaps, ability to show regions where saturation processes and strong doppler shifting are occurring.

The establishment of the 'validity' of such a new statistical method is difficult. One anonymous reviewer has been helpful in this regard, and we therefore now discuss some of the problems associated with the above interpretation. First, a positive statement: regions in height and time where the correlation vectors are large and consistent in direction are likely regions of significant saturation, doppler shifting and anisotropy of GW directions. Secondly, some concerns: it is likely that at certain heights/times the GW propagation directions will not be strongly anisotropic and the various phase velocities will superimpose and cancellation may occur; it is also possible that given the smaller GW intensities at the higher frequencies (associated with a $-5 / 3$ slope, Zhan et al., 1996) saturation for waves travelling opposite to the wind may not occur. For the former problem, this will lead to smaller correlations, with poorly determined directions. Indeed in Manson et al., 1998b, the GW-modulations by tides were very intermittent in winter, and the "correlation vectors" also showed small magnitudes and variable directions. For the second problem, the method may in fact be somewhat selective of particular GW periods, and care should be taken in interpretations. However, the periods used (10-150 min.) are widely considered to be very important for momentum deposition processes (e.g. Fritts, 1989) so information from the associated "correlation vectors" will be valuable.

Finally, other independent tests of the new method should proceed elsewhere. The GW band outputs from the most sophisticated and high resolution GCMs will be valuable, and such work is proceeding. Ray tracing could also be valuable here, and we note that the work of Zhong et al. (1996) on exclusion circles does confirm the simple expectations for pre- ferred GW propagation directions in the solstitial mesopause region. The use of the new method in this paper offers further opportunities to test and compare its predictions with other spectral methods-consistency of inferences about GW directions is a useful 'validation' method.

The only significant difference between data sampling at the 7 MFRs, is that the three low latitude (Yamagawa to Christmas Island) systems used 2-min. sampling rather than 5 -min. The effect of this upon the spectra was very carefully assessed using Saskatoon data of both sampling rates. It was found that a dependence of variance upon record-length ( 2 min. or 4-5 min.) exists, and suitable normalization was applied. Sampling at 5-min. intervals was then done for all MF systems, and frequency spectra from $(10 \mathrm{~min} \text {. })^{-1}$ to $(10.7$ hrs. $)^{-1}$ produced. All available spectra for a given month (station) were included in the monthly means.

Two difference-filters have also been applied to the data; these are particularly valuable when there are gaps in time sequences. The first is applied to consecutive wind vectors, which are obtained every $5 \mathrm{~min}$; this process is equivalent to a band-pass filter of 10-100 min., and has been discussed in some detail by Nakamura et al. (1993). The second is applied to hourly mean data (Gavrilov et al., 1995), and is equivalent to a band-pass filter of approximately 1.5-6 hrs. The r.m.s. outputs from these filters may be described in terms of horizontal wind-perturbation ellipses, or more properly "ovals" (hereafter "perturbation ovals"). On a timescale of one month, these are used to demonstrate variations in GW variances (from the relative magnitudes of the major axes) and predominant $\mathrm{GW}$ propagation directions (from the major axes; uncertain by 180 degrees).

Normalization as described above was also applied to the ovals from stations sampling at 2-min. intervals. Hourly mean winds were included in the second filter if there were $>3 />7$ samples of the possible $12 / 30$ in an hour. Significance levels were calculated (Gavrilov et al., 1995) as to whether the degree of elipticity or departure from circularity was meaningful, given the number of points or values used for the calculation of the ovals. Generally, the numbers of values in a month for the height layer used at $76-88 \mathrm{~km}$ are so large (several thousand), that all ovals later plotted have significance of orientation/elipticity of at least $95 \%$ and usually 99\%. The "ovals" are used in Section 5.

\section{Frequency Spectra}

A distinctive variation emerged for these in the first paper (MMZ). The frequency spectra for MFRs in the Prairies (Saskatoon, Robsart, Sylvan Lake) all showed a very similar monthly pattern of slope-variation: "near $-5 / 3$ for winter months, but slopes closer to -1 for higher frequencies $(\tau<$ 2 hrs.) in summer and neighbouring equinoctial months". The integrated spectral densities, or the spectral intensities, did change by month, demonstrating a SAO in the EW and NS component plots. There were also differences between intensities of components (NS, EW), which varied with location, and which were related by means of "perturbation ovals" to GW polarization changes with time and location. Both of these two latter will be explored below. We initially focus upon the climatologies of the spectra, in particular the seasonal trends in their slopes. 
|
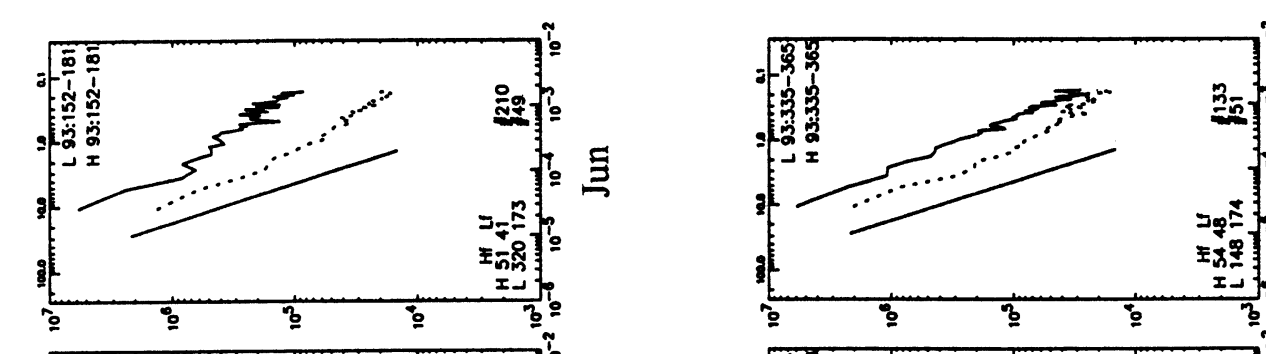

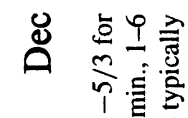

ㄷㅇㅇㅝ
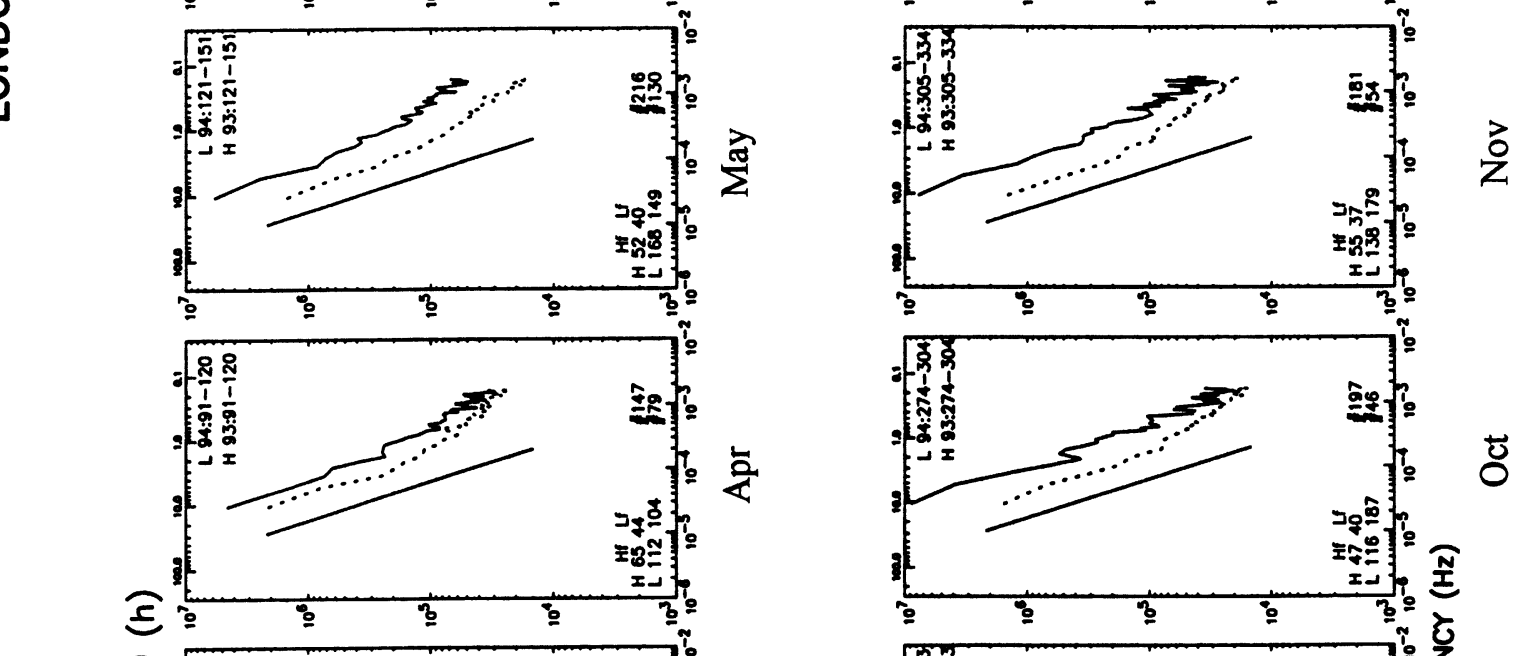

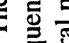

金奠

乙至要

पु స్రิ

实
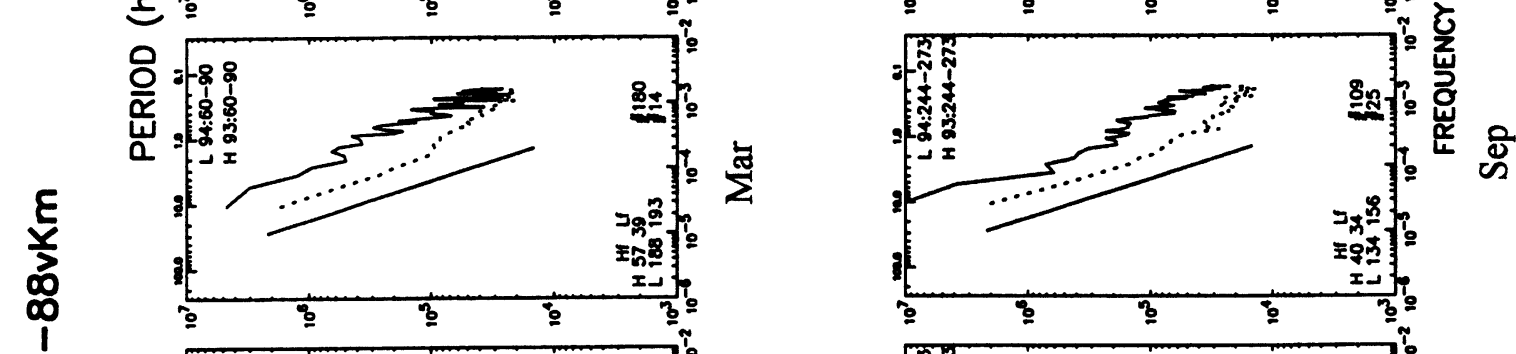

总

乙驾

要要

实 흥

襃

迎 密

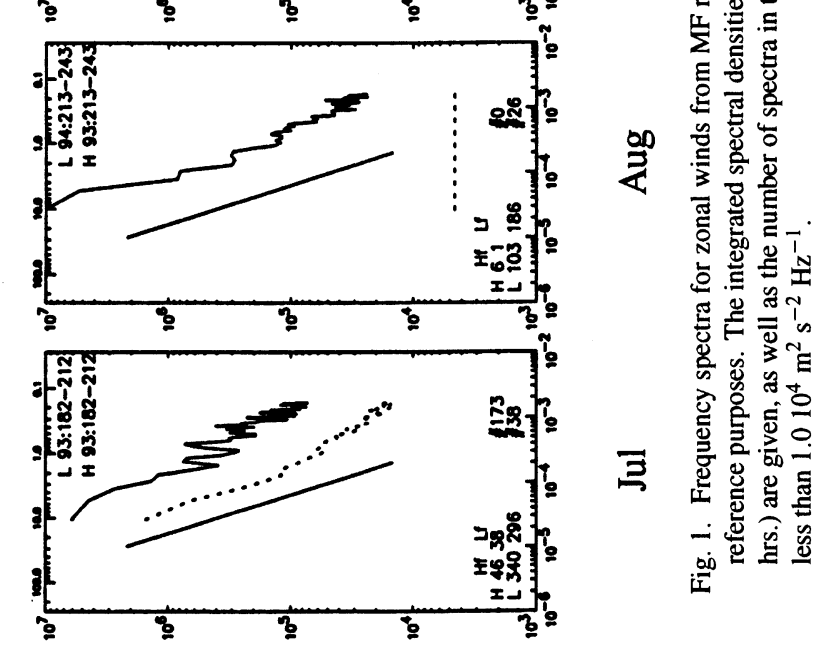


We will show spectra from two locations to illustrate the two types of spectra. Spectra from Troms $\varnothing$ to Urbana showed the same pattern as in the Prairies, i.e. a more shallow slope at higher frequencies ("turn-up") in summer and neighbouring equinoctial months. Spectra from Yamagawa to Christmas Island also showed this high frequency slope change in each month. Figure 1 shows the London and Hawaii spectra as our case examples: February and December are very clear winter examples, while May and June are good summer examples. There are a few other obvious effects. Firstly, the London GW intensities are considerably larger than at Hawaii; this will be discussed later when all locations are considered in Section 6. Secondly, and related to the slope changes, the high-frequency spectral densities are more similar for these two (low- and mid-latitude) stations than are the low-frequencies. Thirdly, there are no substantial differences between the monthly slope-variations in the EW and NS (not shown) component spectra. (This was also noted in the earlier MMZ study.)

The monthly changes in intensity at high and low frequency may affect the changing slopes of the spectra, and their relative placement in the figures. This is now addressed.

\section{Dependence of Spectral Intensity upon Wind Speed}

This theme was explored very thoroughly in the earlier paper. We again summarize that. The monthly changes (76$88 \mathrm{~km}$ ) in spectral slopes (EW component) for the Saskatoon radar showed no clear correlation with mean zonal wind i.e. the magnitude and timing of the monthly changes did not consistently follow the evolution of the wind as it changed from winter to summer and vice versa. The theoretical development of Fritts and VanZandt (1987), in which they consider the Doppler shifting of GW, was shown to be consistent with that. For typical values of their beta parameter (mean wind divided by intrinsic phase speed) the slope change was very small from near the Väisälä-Brunt period ( $\sim 5 \mathrm{~min}$. to $\sim 90 \mathrm{~min}$.), but there were enhanced spectral densities. Beyond there the slopes became smaller (more positive), with diminished spectral densities.

The earlier observations and analyses were consistent with the modelling of Fritts and VanZandt (1987) in two ways. First, the monthly integrated spectral densities (10-100 min.) for the GWs (EW components) followed the strengths of the mean zonal winds well. Second, spectra within each month were classified according to the strengths of the wind for the $10.7 \mathrm{hrs}$. of data (used for each spectra). Generally, throughout the year, the spectral intensities for speeds greater than $20 \mathrm{~m} \mathrm{~s}^{-1}$ were $40-100 \%$ higher than for speeds $<20 \mathrm{~m} \mathrm{~s}^{-1}$. The spectra for this lowest speed-range $\left(<20 \mathrm{~m} \mathrm{~s}^{-1}\right)$ were remarkably similar in slope and intensities for each month of the year - the residual variations (no longer SAO) will be due to sources and wave interactions below $76 \mathrm{~km}$. Rastogi et al. (1996) have suggested that a spectral "turn-up" at high frequencies would be caused by horizontal gradients in vertical wind component (likely due to GW activity). While this effect may be inherent in the observed spectra (in MMZ, and in this paper), it is emphasized that spectra obtained under low wind-speed conditions have little "turn-up" and are closer to $-5 / 3$ in slope.

\subsection{London $\left(43^{\circ} \mathrm{N}\right)$ and locations from Tromsø $\left(70^{\circ} \mathrm{N}\right)$ to Yamagawa $\left(32^{\circ} \mathrm{N}\right)$}

Here we have devised an analysis method that will illustrate this effect more clearly on a monthly basis, for both GW bands (10-100 min., 1-6 hrs.) and for stations other than Saskatoon. For each month and for each spectrum, we shall plot the integrated spectral densities (variances) versus the mean speed of the wind for the time sequence used (EW component). Scatter plots for each month will be produced, and a line of best-fit plotted. The correlation coefficients will be shown.

The scatter plots for London are shown for both GW bands. (Figures 2 and 3). The number of positive or negative slopes in total, and at the $95 \%$ significance level for the number of points involved, are shown in Table 1. At high frequencies the slopes are consistently positive (12 cases, 11 at 95\%), as would be expected from the earlier Saskatoon analysis. The slopes are also positive at the lower frequencies, which differs from the earlier Saskatoon results. (11 cases, 9 at $95 \%$ ). A reviewer has commented on these scatter plots, and the existence of two groups of points in some months e.g. May. This has been carefully investigated. Some of the higher intensity points are from sequences with more gaps in these months; they contribute some noise. However, the signs of the correlations $\rho$ (and signs of line-slopes) are not sensitive to modified analyses in such months, although the magnitudes of $\rho$ may increase. The magnitudes of slopes within scatter plots are frequently problematic e.g. depending on choice of scaling, but it is the sign (and magnitude) of $\rho$ and not the magnitude of the lines slope which is important here. Hence the signs of $\rho$ in Figs. 2 and 3, and Table 1 are considered very robust, due to overall appropriate choice of data.

There is also a preference for positive slopes at high frequencies for all mid- to high-latitude stations (Yamagawa to Troms $\varnothing$ ) as indicated in Table 1 . We also show as another example the high frequency scatter plots for Urbana (Fig. 4) whose total number of positive slopes (8), and at the $95 \%$ significance level (5), are typical of the other stations. Note however (Table 1) that negative slopes are generally more common for the low frequency band (this spectral density decrease had been noted before at Saskatoon). It should also be noted that generally the favoured (tabulated) slope sign is most characteristic and significant e.g. at Saskatoon (10$100 \mathrm{~min}$.) the 5 slopes that are not positive have small gradients (V mean/spectral density), and are weakly significant. The only departure from this generality is for low frequencies at Yamagawa. The uniqueness of London, with its positive slopes at low frequencies, may have to do with a probable local difference of the distribution of GW phase speeds (both observed and intrinsic) and the related effect upon the value of beta (Fritts and VanZandt, 1987). There have indeed already been suggestions by Thayaparan et al. (1995), based upon tidal studies, that local GW activity associated with the Great Lakes and related weather activity is significant for middle atmosphere dynamics. Finally, it is apparent from the Table that Yamagawa $\left(32^{\circ} \mathrm{N}\right)$ is at a transition between mid-latitude and low-latitude behaviours, as the numbers of positive/negative slopes for high/low frequency GW bands are the smallest for all mid- to high-latitude locations. 


\section{London (43 N)}
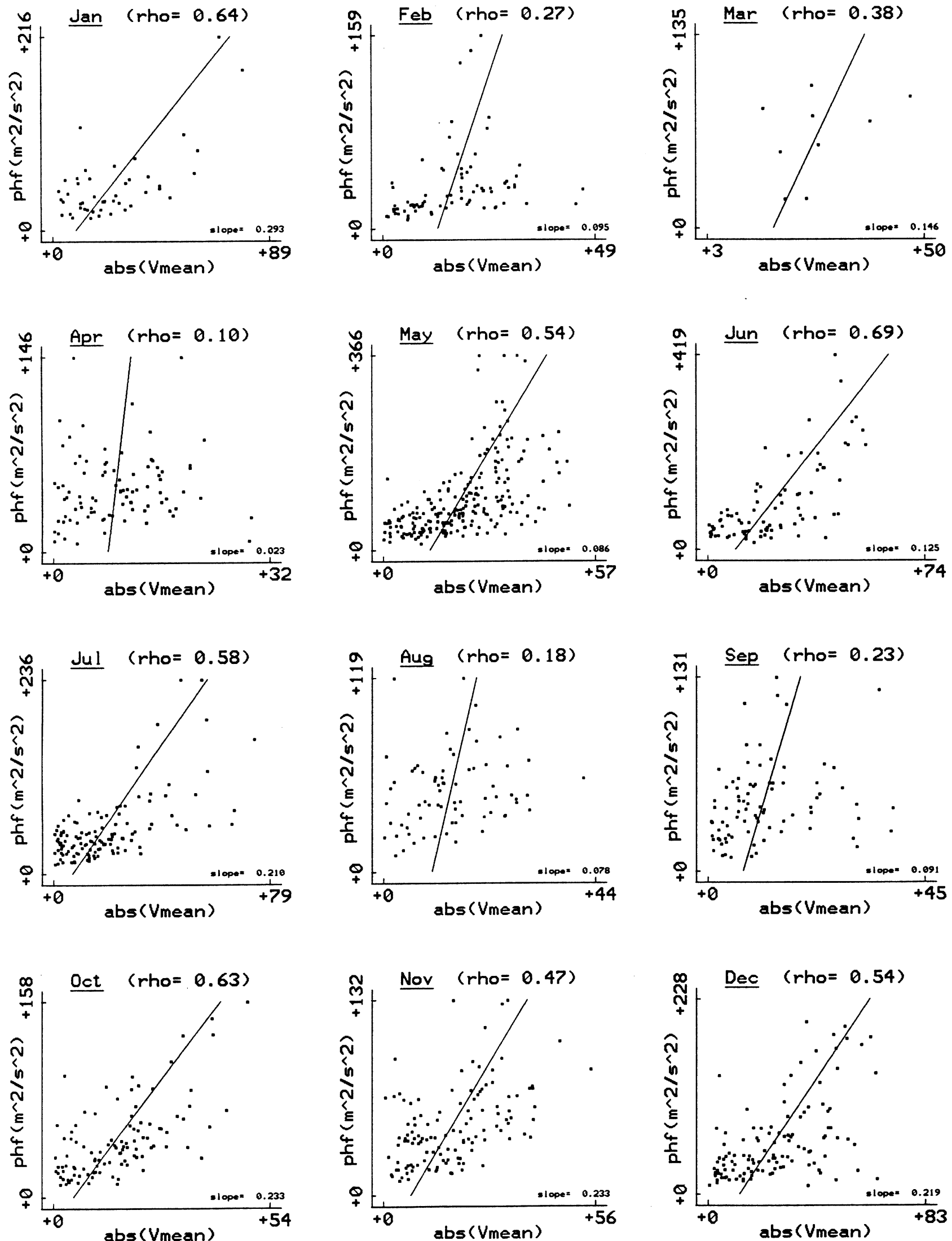

Fig. 2. Integrated spectral densities (zonal components), for periods of 10-100 min., plotted versus the mean speed of the wind for each time sequence used: London $\left(43^{\circ} \mathrm{N}\right)$. The data complement Fig. 1: height range $76-88 \mathrm{~km}$, years 1993/4. The line of best-fit is plotted, along with the correlation coefficient and slope of the line. 


\section{London (43 N)}
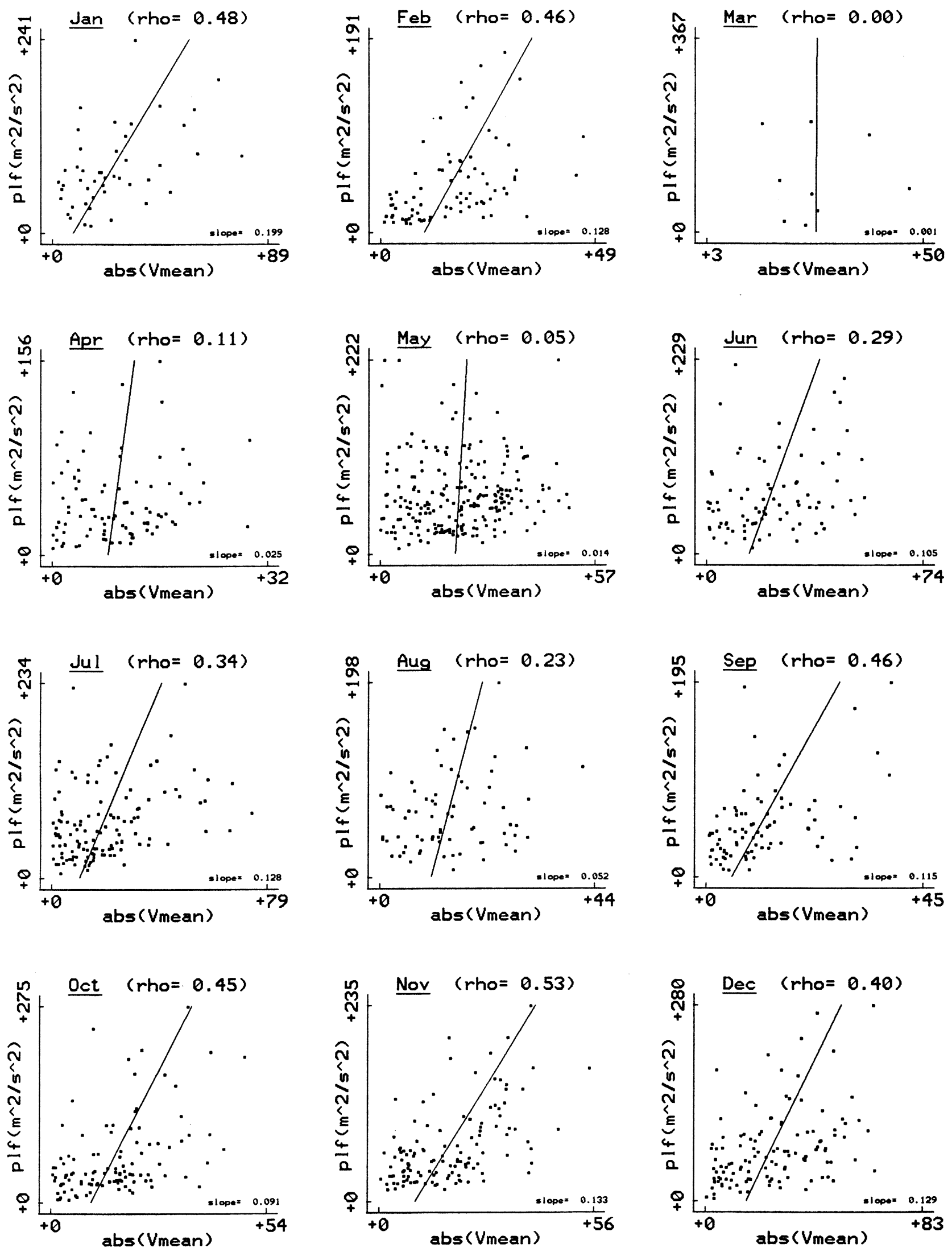

Fig. 3. Integrated spectral densities (zonal components), for periods of 1-6 hrs., plotted versus the mean speed of the wind for each time sequence used: London $\left(43^{\circ} \mathrm{N}\right)$. The data complement Fig. 1: height range $76-88 \mathrm{~km}$, years $1993 / 4$. The line of best-fit is plotted, along with the correlation coefficient and slope of the line. 


\section{Urbana (40N)}
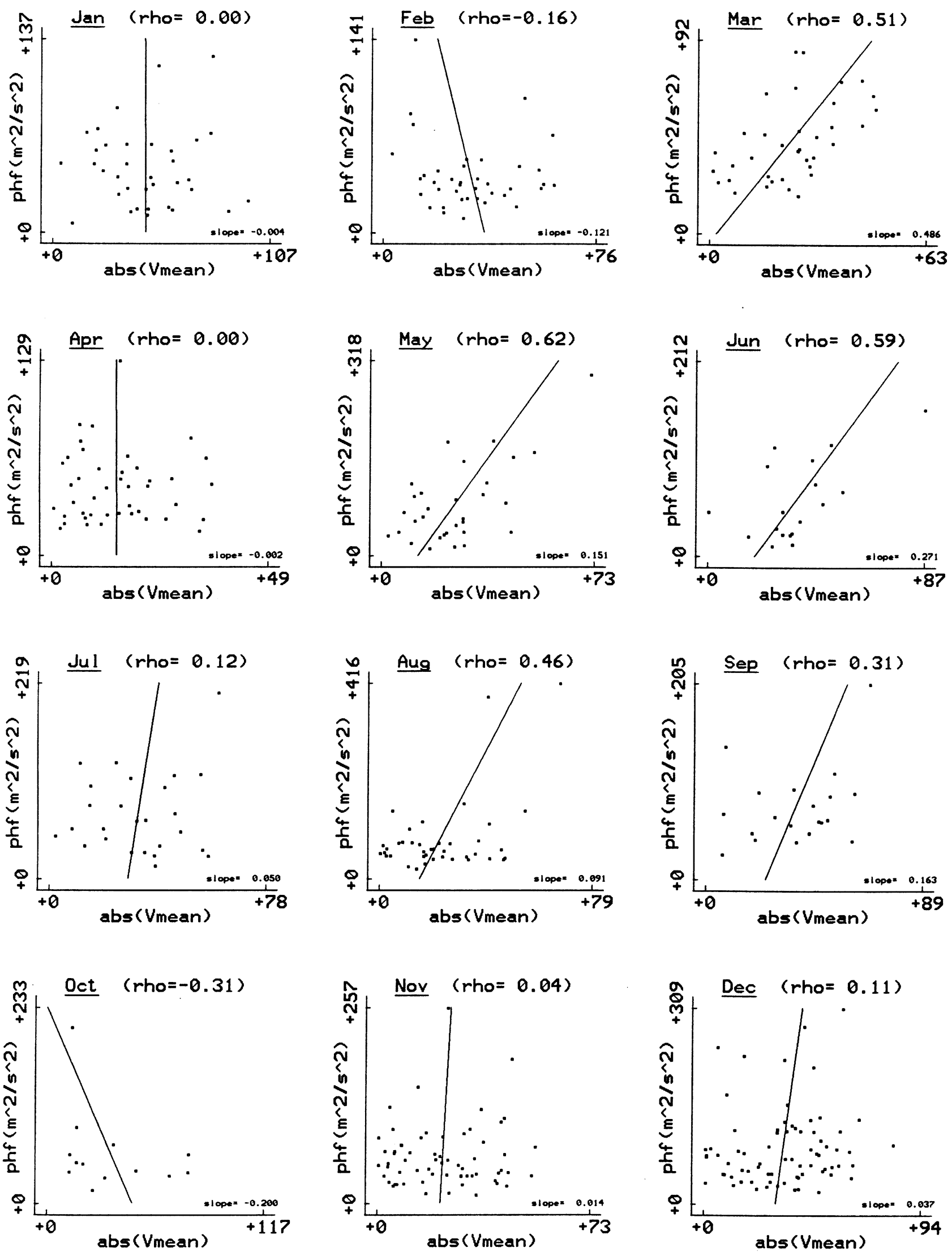

Fig. 4. Integrated spectral densities (zonal components), for periods of 10-100 min., plotted versus the mean speed of the wind for each time sequence used: Urbana $\left(40^{\circ} \mathrm{N}\right)$, height range $76-88 \mathrm{~km}$, year 1992 . The line of best-fit is plotted, along with the correlation coefficient and slope of the line. 
Table 1. Results from plots of integrated spectral densities for two GW bands versus wind speed (EW component).

\begin{tabular}{|c|c|c|c|c|c|c|c|c|}
\hline \multirow{3}{*}{$\begin{array}{l}\text { Location } \\
\text { Troms } \varnothing\end{array}$} & \multicolumn{4}{|c|}{$\begin{array}{l}\text { High frequency } 10-100 \mathrm{~min} \text {. } \\
\text { Number of slopes (+ or }- \text { ) }\end{array}$} & \multicolumn{4}{|c|}{$\begin{array}{c}\text { Low frequency } 1-6 \mathrm{hrs} \text {. } \\
\text { Number of slopes }(+ \text { or }- \text { ) }\end{array}$} \\
\hline & \multicolumn{2}{|c|}{ Total } & \multicolumn{2}{|c|}{ Number, $>95 \%$} & \multicolumn{2}{|c|}{ Total } & \multicolumn{2}{|c|}{ Number, $>95 \%$} \\
\hline & 7 & + & 5 & + & 10 & - & 6 & - \\
\hline Saskatoon & 7 & + & 6 & + & 8 & - & 6 & - \\
\hline London & 12 & + & 11 & + & 11 & + & 9 & + \\
\hline Urbana & 8 & + & 5 & + & 6 & - & 3 & - \\
\hline \multirow[t]{2}{*}{ Yamagawa } & 6 & + & 4 & + & 5 & - & 2 & - \\
\hline & 3 & - & 2 & - & 4 & + & 2 & + \\
\hline Hawaii 1993 & 6 & - & 2 & - & 10 & - & 5 & - \\
\hline Hawaii 1994 & 10 & - & 5 & - & 10 & - & 5 & - \\
\hline Christmas Is. & 11 & - & 9 & - & 8 & - & 7 & - \\
\hline
\end{tabular}

\section{London $(43 \mathrm{~N})$}
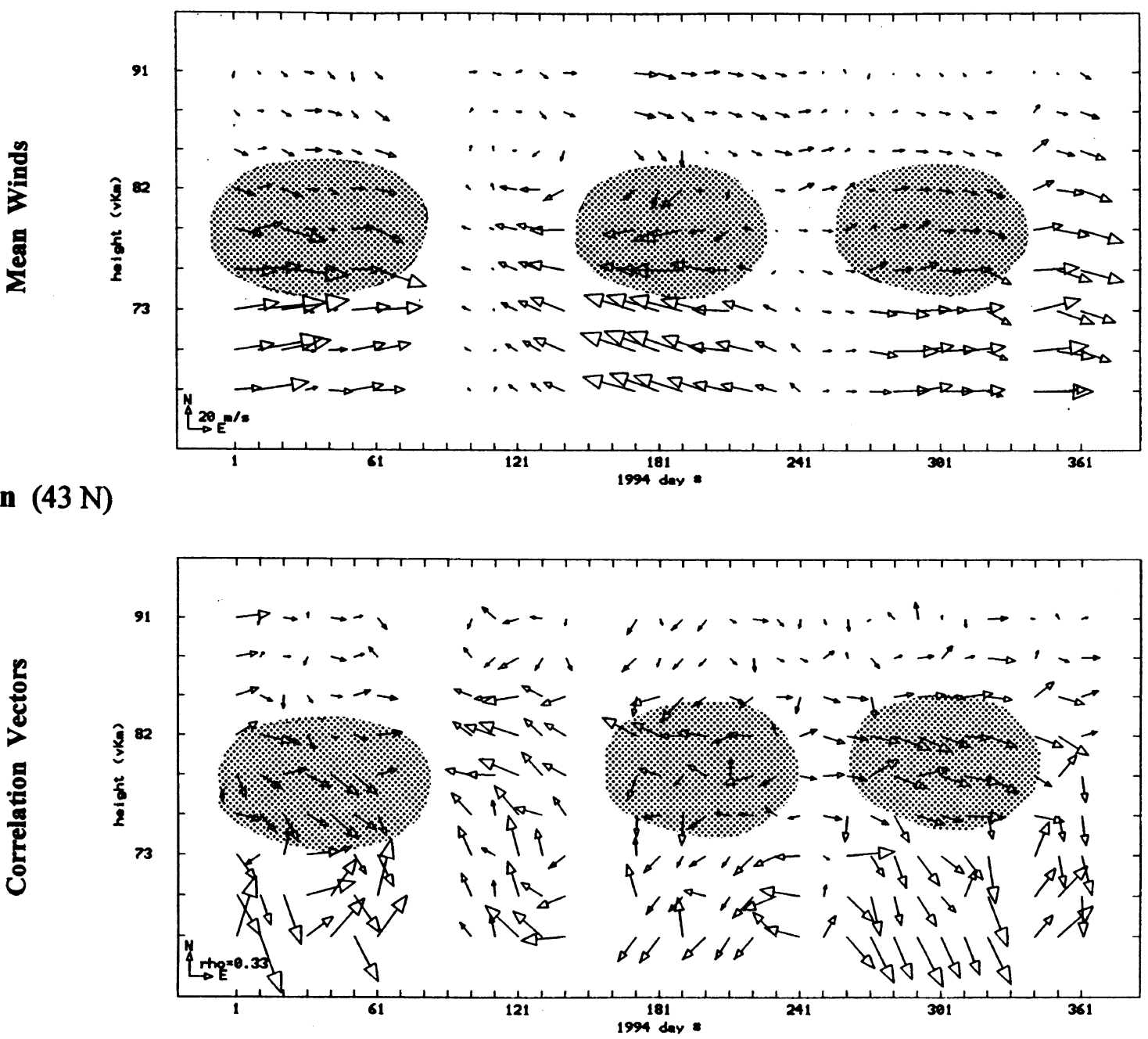

Fig. 5. Mean 10-d winds, and correlation vectors (over 10 days) for London $\left(43^{\circ} \mathrm{N}, 1994\right)$. The correlations are between hourly mean winds and their standard deviations (sd) over all azimuthal directions (Section 4). The circled regions are discussed in the text. The altitudes are in virtual heights ( $\mathrm{v} \mathrm{km}$ ), which are also geometric heights below $94 \mathrm{~km}$. 


\section{Hawaii (22N)}
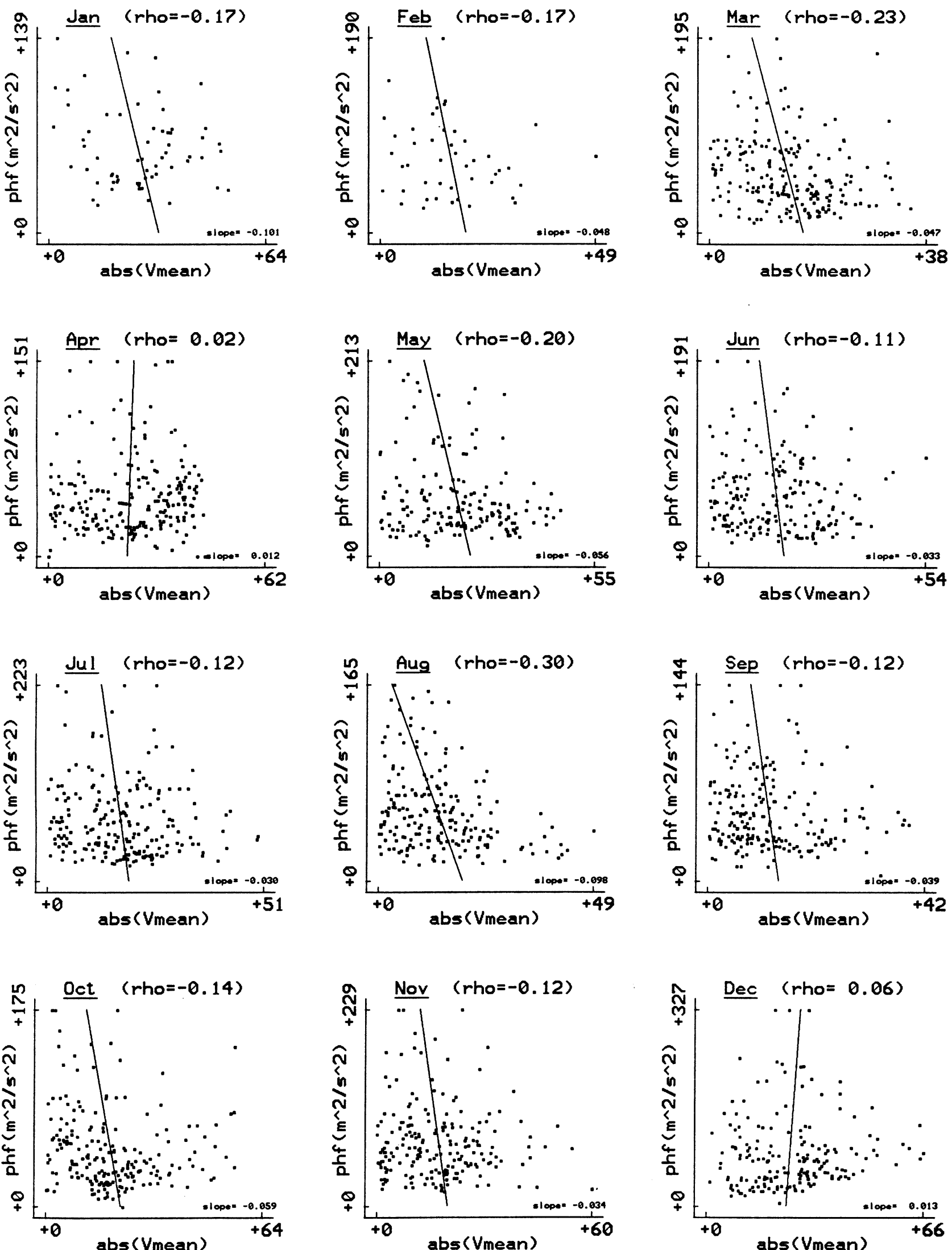

Fig. 6. Integrated spectral densities (zonal components), for periods of 10-100 min., plotted versus the mean speed of the wind for each time sequence used: Hawaii $\left(22^{\circ} \mathrm{N}\right)$. The data complement Table 1: height range $76-88 \mathrm{~km}$, year 1994 . The line of best-fit is plotted, along with the correlation coefficient and slope of the line. 


\section{Hawaii $(22 \mathrm{~N})$}


Fig. 7. Integrated spectral densities (zonal components), for periods of 1-6 hrs., plotted versus the mean speed of the wind for each time sequence used: Hawaii $\left(22^{\circ} \mathrm{N}\right)$. The data complement Table 1: height range $76-88 \mathrm{~km}$, year 1994 . The line of best-fit is plotted, along with the correlation coefficient and slope of the line. 


\section{Christmas Island $(2 \mathrm{~N})$}
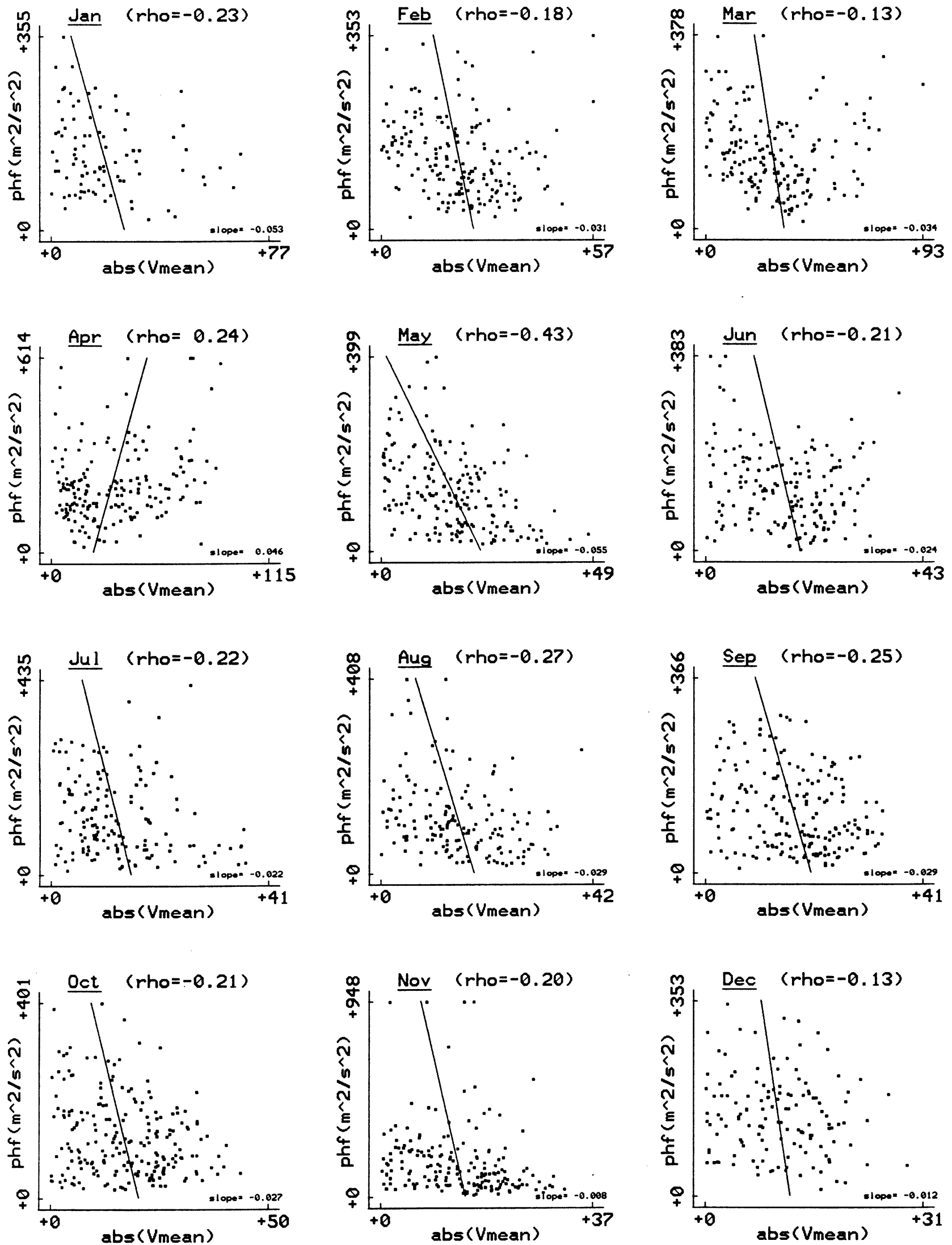

Fig. 8. Integrated spectral densities (zonal components), for periods of 10-100 min., plotted versus the mean speed of the wind for each time sequence used: Christmas Island $\left(2^{\circ} \mathrm{N}\right)$. The data complement Table 1: height range $76-88 \mathrm{~km}$, year 1993 . The line of best-fit is plotted, along with the correlation coefficient and slope of the line. 


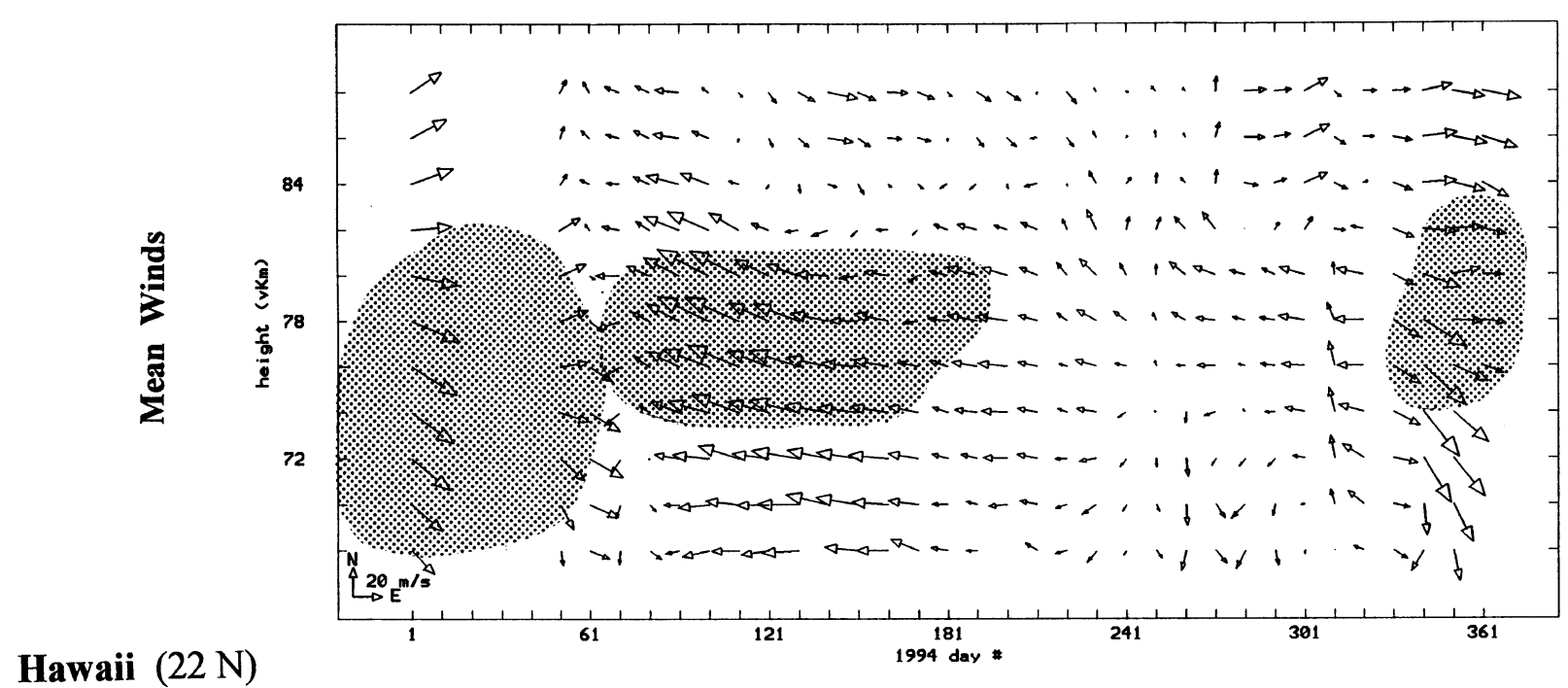

Hawaii $(22 \mathrm{~N})$



Fig. 9. Mean 10-d winds, and correlation vectors (over 10 days) for Hawaii $\left(22^{\circ} \mathrm{N}, 1994\right)$. The correlations are between hourly mean winds and their standard deviations (sd) over all azimuthal directions (Section 4). The circled regions are discussed in the text. The altitudes are in virtual heights ( $\mathrm{v}$ km), which are also geometric heights below $94 \mathrm{~km}$.

We have chosen to discuss this result by the use of additional analysis before considering the low latitude behaviour. The method is the "correlation vector" analysis described in some detail already in Section 2. In Fig. 5, we show the 10-d Correlation vectors over the 1994 year for London, from 67$91 \mathrm{~km}$. Also, above, are the 10-d mean winds. The variations of the hourly mean winds about these means will be mainly due to tides, but also inertial-GW and PW. It is evident that in the region of strongest zonal shear, $76-82 \mathrm{~km}$, where momentum deposition will be greatest and saturation processes important (as indicated by all sophisticated GCMs), the correlation vectors are generally parallel to the mean winds. As discussed at some length in Section 2, this is consistent with GW directions being eastward in summer-like months, and westward in winter-like months (providing saturation is occurring in the 10-150 min. band). This result is even clearer than at Saskatoon (not shown), as perhaps is to be expected given the stronger solstitial jets, and the required larger momentum depositions for reversal.

This result of Fig. 5 is of course physically quite consistent with the results of Figs. 2 and 3, and Table 1. There is only a slight difference as to which of the longer-period waves are affecting the analysis. For the latter (spectral densities), variations of the mean wind (10.7-hr. values) will be affected by 24-hr. tides and PW; whereas for the former (correlation vectors) 12-hr. tides and inertial-GW will also be responsible. The other stations (Troms $\varnothing$ to Yamagawa) all show this inferred result of GW propagations anti-parallel to the mean flow. These are all locations where significant vertical shear of the zonal flow exists in the solstices, and associated GW momentum depositions are required. This appears to be useful observational evidence for these hypothesized processes, and to some degree an indication of the value of the new 'correlation vector' method.

\subsection{Hawaii $\left(22^{\circ} \mathrm{N}\right)$ and the equatorial station (Christmas Island).}

Here we repeat the analysis of Subsection 4.1 above, and choose Hawaii as the main station-example again. Two years (1993/4) are available for the scatter plots of variances, and two GW bands (Table 1). We show the high/low frequen- 

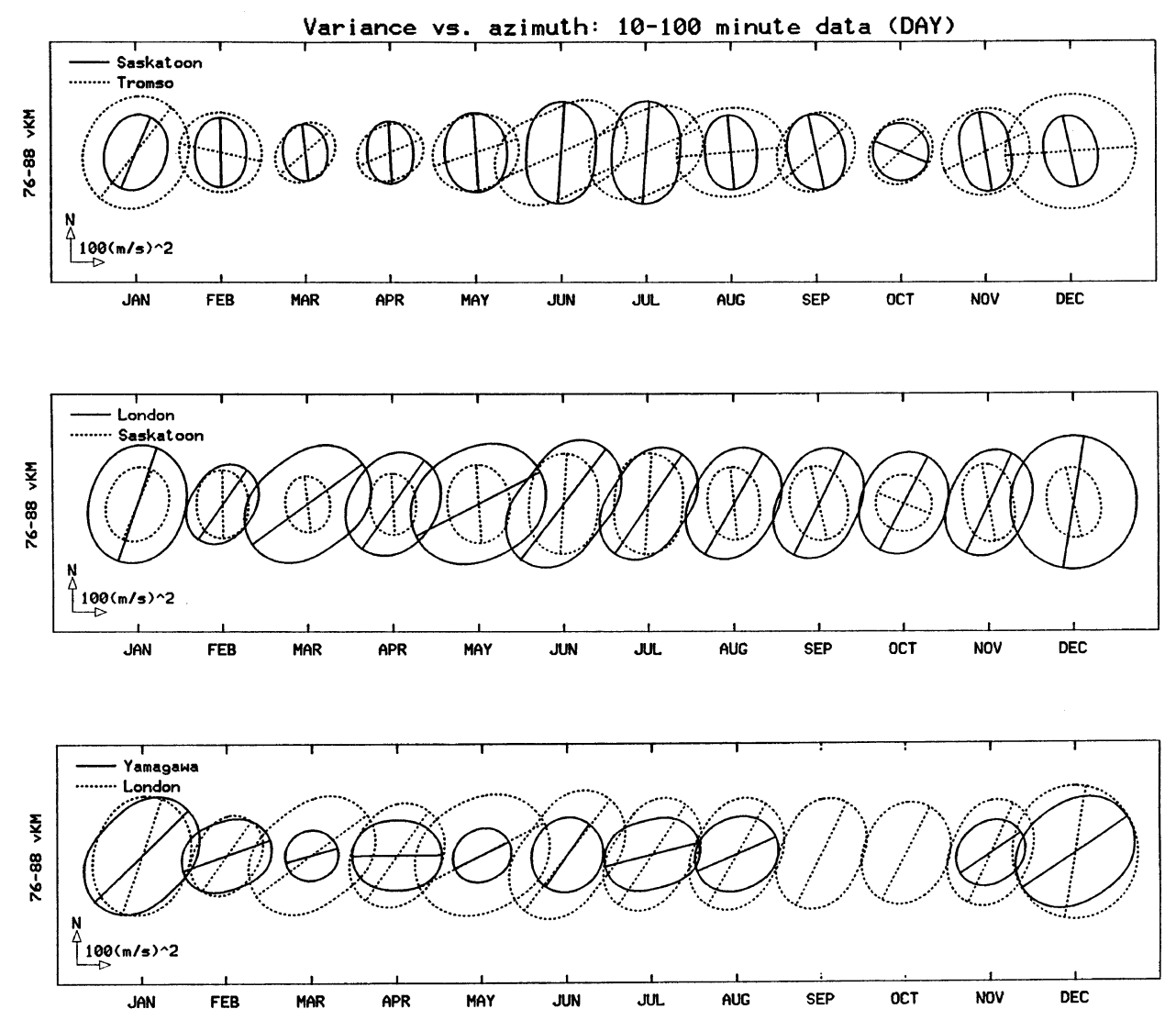

Fig. 10. Ovals of wind spectral variance in the band $10-100 \mathrm{~min}$. for the height layer $76-88 \mathrm{~km}$, for 4 locations: Troms $\emptyset\left(70^{\circ} \mathrm{N}, 1994\right)$, Saskatoon $\left(52^{\circ} \mathrm{N}\right.$, 1994), London ( $\left.43^{\circ} \mathrm{N}, 1994\right)$, Yamagawa $\left(32^{\circ} \mathrm{N}, 1996\right)$.

cies for 1994 (Figs. 6 and 7). There are clear preferences for negative slopes (10 cases, 5 at 95\% significance for both bands), meaning that decreased variances are associated with increased wind speeds. From the table the Christmas Island case is even more significant, and for both GW bands; as an example the high frequency scatter plots are also shown (Fig. 8). Notice that in April only, is there a strong positive correlation and slope. This will be commented upon with regard to the next analysis. We move now to the "correlation vector" analysis. The 10-d mean winds and the associated correlation vectors for Hawaii are shown in similar fashion (Fig. 9) to those for London (Fig. 5). Differences from midlatitudes are again expected and are indeed seen. For the heights $76-82 \mathrm{~km}$, previously considered for London, the correlation-vectors are now anti-parallel to the flow, consistent with GW propagating parallel to the flow e.g. in summerlike months a more eastward flow (decreasing westward) leads to increasing variances. This relationship is physically consistent with the inferences drawn from the negative-slopes in the scatter plots of Figs. 6, 7, and 8 (and Table 1). The two statistical methods are, of course, investigating the same process, although the 'correlation vectors' do give additional direction information. It is interesting that for days 81-121, and above $81 \mathrm{~km}$ where the zonal shear is again large, the correlation vectors reverse, and eastward propagating GW are again inferred. This direction is opposite to the flow. It should be noted that the vector plots for Christmas Island are similarly diagnostic for the full year. Finally, we observe that the scatter plots for Hawaii and Christmas Island (Figs. 6 and 8; high frequency) evidence a tendency toward positive slopes for the spring month of April, consistent with changing GW characteristics. Due to the uniqueness of low-latitude wave processes, and the semi-annual oscillation (SAO) and QBO variability (R. A. Vincent, private communication, 1998), these locations will be the focus of more detailed GW studies elsewhere. At this point however it is clear that high/mid-latitudes and low/equatorial latitudes have strikingly different GW-mean flow interactions, as associated with the major features (vertical shear of the zonal flow) of the circulation.

These results are worthy of further discussion in the context of Section 2, and the "correlation vector" method. The result that decreased GW variances are associated with increased (background) wind speeds has been found from two statistical methods; the plots of variances versus wind speed (Figs. 6 and 8, and Table 1) and the correlation vectors (Fig. 9). There are minimal physical assumptions in those methods. The correlations are relatively large and coherent in the regions of interest in Fig. 9, suggesting anisotropy of the GW directions. Upon further reflection, the two methods used for Figs. 6, 8, and 9 are largely equivalent in their approaches; the clearest advantage of Fig. 9 is in the visual presentation, and the seasonal view of changing wind directions. Any physical interpretation developed from these 



Fig. 11. Ovals of wind spectral variance in the band $10-100 \mathrm{~min}$. for the height layer $76-88 \mathrm{~km}$, for 4 locations: Yamagawa $\left(32^{\circ} \mathrm{N}, 1996\right)$, Hawaii $\left(22^{\circ} \mathrm{N}, 1993 / 4\right)$, Christmas Island $\left(2^{\circ} \mathrm{N}, 1993\right)$, Saskatoon $\left(52^{\circ} \mathrm{N}, 1994\right)$. For the Christmas Island/Hawaii comparisons 1993 data are used; and for Hawaii/Saskatoon the 1994 data are used.

common statistical results does require assumptions. For example, a possible 'summer' scenario for Fig. 9 is that the GWs dominating the analyses near $80 \mathrm{~km}$ (periods between $10 \mathrm{~min}$. and several hours) are largely westward propagating, due to either sources or filtering below, and changes in their amplitudes and or numbers are leading to correlations. Saturation could be involved, but indeed non-saturation also; in the latter case, decreased westward winds could allow more waves to penetrate the region, and hence to provide greater variance. These results will be elaborated upon as campaigns with SCOSTEP's EPIC (Equatorial Processes Including Coupling) are developed.

We do note in conclusion that mesospheric wind results from UARS, for equatorial/tropical regions, are consistent with our unique low latitude GW results. McLandress (1998) shows a SAO-modulated eastward mean (background) wind centred on $65 \mathrm{~km}$ altitude ( $30 \mathrm{~m} / \mathrm{s}$ maxima) for the equator; with out-of-phase SAO in the westward flow centred on 80 $\mathrm{km}$. (Our wind observations match these, and are centred on the latter region.) Thus GW with phase velocities below $30 \mathrm{~m} / \mathrm{s}$ are likely to be westward propagating, and to contribute to the $\mathrm{SAO}$ near $80 \mathrm{~km}$. Indeed our suggestions for westward GW during much of the year also match this. The nature of the dominant GW-wind physical interactions there, and throughout the middle atmosphere, are still being debated, as noted by McLandress at length in a section on GW-parameterizations. Again our suggested interpretations (paragraph above) are consistent with this range of processes: saturation; or non-saturation with fluxes being modified by filtering and critical-level interactions. The eagerly awaited EPIC results, comprising more detailed studies than ours, and including source and velocity distributions, will allow clarifications to be developed.

\section{Ovals of Wind Variance: GW Preferred Direc- tions $76-88 \mathrm{~km}$}

\subsection{0-100 $\mathrm{min}$. band}

This theme was also carefully assessed for the Prairies and at Troms $\varnothing$ in the earlier paper (MMZ, 1997). The ovals show the azimuthal variation of GW variance in a given band. As such they provide information on monthly variations in GW variances (relative magnitudes of major axes), predominant propagation directions (from major axes, \pm 180 degrees), and anisotropy of directions (ratio of major to minor axes). Ratios of major to minor axes usually exceed 1.1, which is greater than a $\sim 95 \%$ significance level for the number of values generally used in determining the ovals. Summarizing; all four locations demonstrated a strong SAO in the size of the ovals, with a summer maximum. There was a dominance of meridional orientations for the major axes at Saskatoon (and Sylvan Lake $52^{\circ} \mathrm{N}$ ), but a strikingly different zonal dominance at Robsart $\left(49^{\circ} \mathrm{N}\right)$. This latter was associated with latitudinal increases in zonal winds providing larger intrinsic GW phase velocities, and with different (NS) 

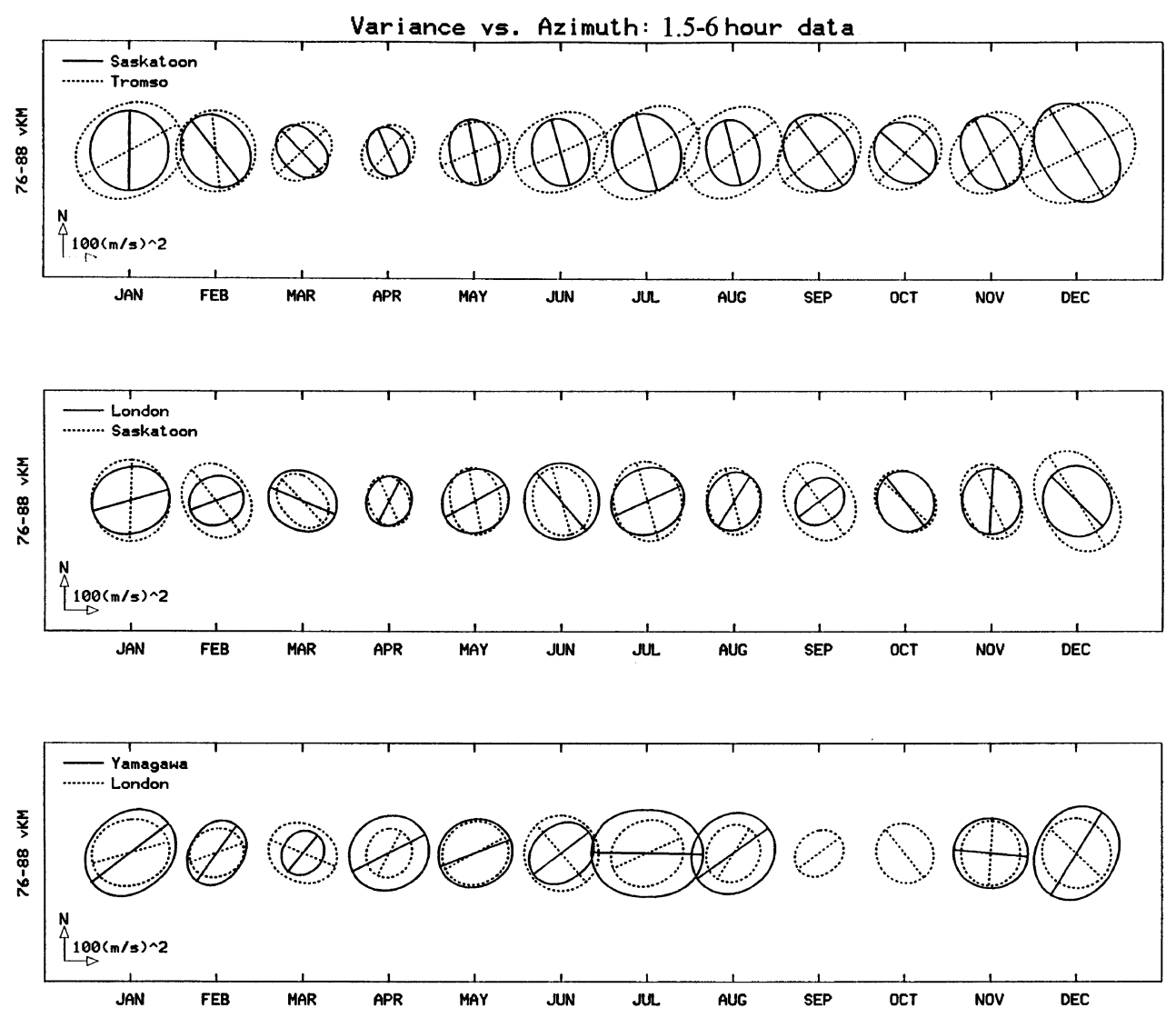

Fig. 12. Ovals of wind spectral variance in the band $1.5-6 \mathrm{hrs}$. for the height layer $76-88 \mathrm{~km}$, for 4 locations: Troms $\varnothing\left(70^{\circ} \mathrm{N}, 1994\right)$, Saskatoon $\left(52^{\circ} \mathrm{N}\right.$, 1994), London ( $\left.43^{\circ} \mathrm{N}, 1994\right)$, Yamagawa $\left(32^{\circ} \mathrm{N}, 1996\right)$.

sources. Troms $\emptyset\left(70^{\circ} \mathrm{N}\right)$ provided larger ovals with zonal orientations, which was considered due to GW source changes in the Fjords; and definitely not to zonal wind increases, as the flow is significantly weaker at such high latitudes.

We show in Figs. 10 and 11 pairs of stations from Troms $\varnothing$ to Christmas Island. The featured location has a solid oval, and the previously plotted higher-latitude site is dotted for comparison; the last section of the figure-pairs shows the Hawaii-Saskatoon combination for a low versus mid/high latitude comparison. Where a choice of years existed, the year providing a same year comparison for neighbours was chosen e.g. Hawaii, Christmas Island 1993; Hawaii, Saskatoon 1994. Interannual variations are usually small at higher latitudes, although notably larger at Hawaii and Christmas Island.

From Troms $\varnothing$ to Yamagawa there is a clear SAO, which is shared by Urbana (this location's GW data are normally very similar to London, and are not shown). There are summer maxima for all but Yamagawa, which has a clear winter maximum. All stations have major axes orientations which are more zonal than at Saskatoon, with the NE-SW quadrant being strongly favoured. Hawaii and Christmas Island are quite distinctive: the $\mathrm{SAO}$ is much less evident with a spring maxima, especially at Christmas Island; directions are NWSE at Hawaii, and strongly meridional at Christmas Island. The differences between low (Hawaii) and mid (Saskatoon) latitudes are very clear in the last section of Fig. 11. Again, as in Sections 3 and 4, the behaviour at low latitudes is dis- tinctive

\section{$5.2 \quad 1.5-6$ hrs. band}

The earlier study showed this band to have unique features. The SAO was found to be weaker, with a winter rather than a summer maximum. The major axis was more zonal (than the 10-100 min. band), and directions often differed from that band. There was less evidence that the mean winds were modulating the variances in this band i.e. through changes in GW intrinsic phase speed.

We show in Figs. 12 and 13 the pairs of stations already considered in the earlier section. Again from Troms $\varnothing$ to Yamagawa (including Urbana) there is a clear, if weaker, SAO. Major axes orientations vary from a frequent NW-SE at mid latitudes to a NE-SW at higher (Troms $\varnothing$ ) and lower latitudes (Yamagawa). There is more variation of majoraxes orientation by month and locations than in the higher frequency GW band. This is consistent with the conclusions reached earlier (MMZ) that sources of GW are more influential in determining these ovals. Hawaii and Christmas Island are quite distinctive: the SAO is quite weak, with spring maxima being evident in this 1993 year; and directions are more meridional in winter-like months, zonal in summer. Finally the Hawaii-Saskatoon comparison is interesting; not only are the ovals similar in size for this 1994 year, but directions are almost identical. It appears that inter-annual variability (perhaps related to the QBO) can be significant here at low latitudes. 

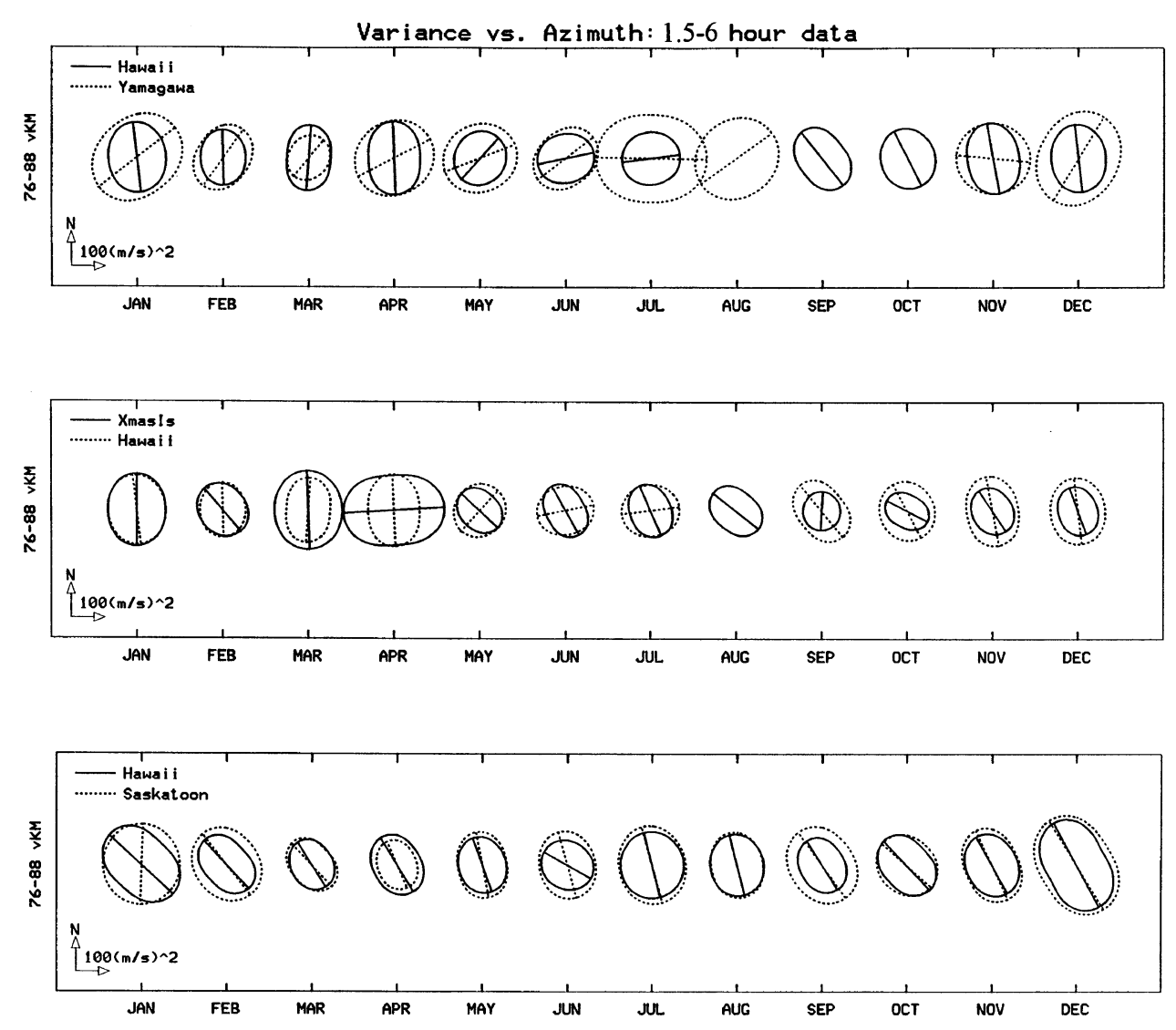

Fig. 13. Ovals of wind spectral variance in the band $1.5-6 \mathrm{hrs}$. for the height layer $76-88 \mathrm{~km}$, for 4 locations: Yamagawa $\left(32^{\circ} \mathrm{N}\right.$, 1996), Hawaii $\left(22^{\circ} \mathrm{N}, 1993 / 4\right)$, Christmas Island $\left(2^{\circ} \mathrm{N}, 1993\right)$, Saskatoon $\left(52^{\circ} \mathrm{N}, 1994\right)$. For the Christmas Island/Hawaii comparison 1993 data are used; and for Hawaii/Saskatoon the 1994 data are used.

\subsection{Comments}

Interpretation of these ovals is not easy at this stage. The dominant propagation directions are certainly much more seasonally variable for the low frequency GW band than for the high. This is consistent with a trend toward longer horizontal wavelengths and higher phase speeds for these waves (Manson, 1990), and their resultant possible lower sensitivity to modulation and filtering by the winds of the middle atmosphere. We do note that lower phase speeds are not excluded for the lower frequency GW band, and that Doppler effects shown in Section 4 also apply to these waves, albeit with somewhat less consistent and weaker trends. However, the low frequency ovals are still probably more dependant upon their GW sources. This was already suggested in the earlier study from the Prairies, where 2 stations (Saskatoon, Sylvan Lake at $52^{\circ} \mathrm{N}$ ) separated zonally by $500 \mathrm{~km}$ had quite differently sized ovals; and where monthly seasonal variations (Saskatoon, $52^{\circ} \mathrm{N}$; Robsart, $49^{\circ} \mathrm{N}$ ) were not strongly dependent upon the mean zonal winds at these heights.

Future published research will be in the area of comparisons between models and observations. An example is the Canadian Middle Atmosphere Model (Shepherd, 1995), where seasonal variations of GW (their intensities, and directions) can be diagnostically compared with these observations (John Koshyk, Private Communications, 1999). Similar studies are being pursued with SKYHI (Kevin Hamilton, Private Communications, 1999). Ray tracing at middle at- mosphere heights (e.g. Zhong et al., 1996; Eckermann and Marks, 1996) on a global scale will also be profitable, as a means of diagnosing and interpreting results such as these. In the meantime, the present results are interesting, unique thus far in their coverage, but not easy to physically interpret. Future EPIC campaigns will also be valuable in this area.

\section{Contour Plots of GW Variances}

It appears useful to complete this initial survey of GW characteristics with contour plots of $\mathrm{GW}$ variances in the 2 bands. This format was not used in the earlier study (due to the lack of latitudinal variation), where time series were used instead. The annual, seasonal variations evident from the ovals (above) are effectively summarized in these final figures. We will show zonal (EW) and meridional (NS) components for both GW bands. There are several alternatives which could have been shown e.g. either integrated spectraldensities for the two frequency bands, or the output of the "difference-filters" (Section 2). Also, given the close proximity of London and Urbana, either or both of these could be shown. It transpires that the choices are not important to the general details of seasonal and latitudinal variations and trends, so that the integrated spectral densities (e.g. as used in Figs. 2 and 3) and the London site are chosen-the latter due to the larger data set (Figs. 14 and 15).

Looking first at the EW (zonal) components, and at high frequencies, the SAO is very clear from Troms $\varnothing$ (Station 6 


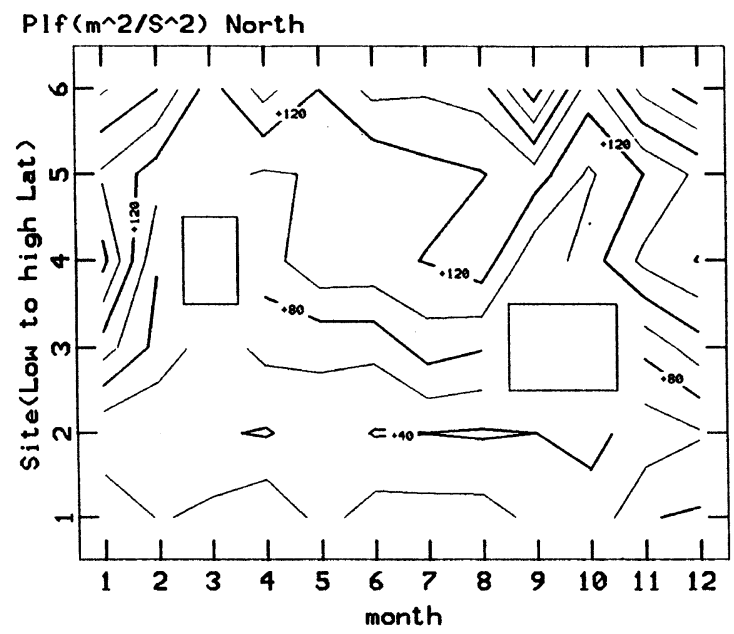

Phf (m^2/s^2) North

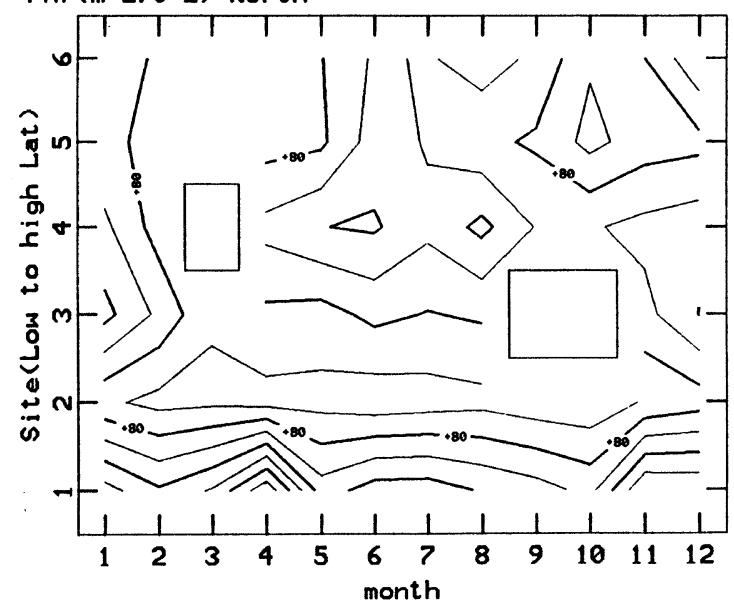

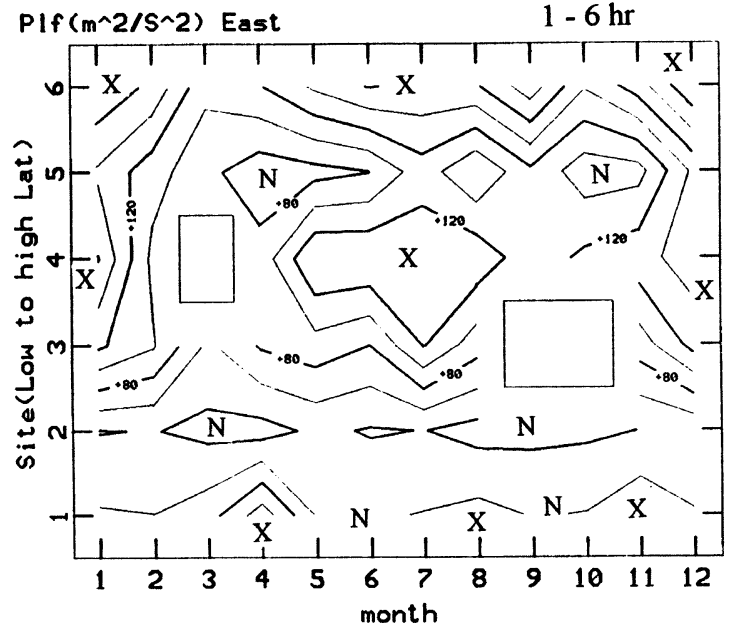

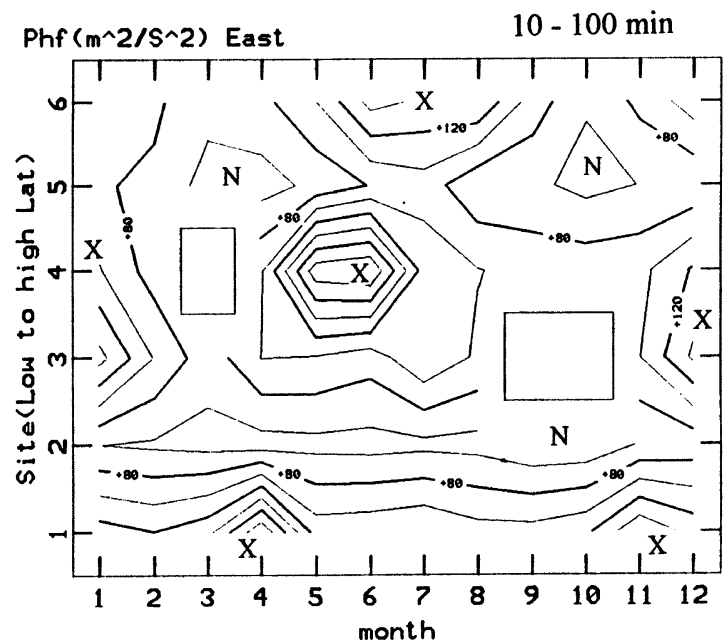

Fig. 14. Integrated spectral densities for low frequencies (Plf, periods 1-6 hrs.) and high frequencies (Phf, periods 10-100 min.) versus month and latitude: 1 (Christmas Island), 2 (Hawaii), 3 (Yamagawa), 4 (London), 5 (Saskatoon), 6 (Tromsø). "East" is the Zonal Component (EW) and "North" the Meridional Component (NS). The regions of maxima or minima may have an X or N for easier identification in the East panels. The contour steps are $20 \mathrm{~m}^{2} \mathrm{~s}^{-2}$. The years are as in Figs. 10, 11, 12, and 13, with both years for Hawaii included.

in the plots) to Yamagawa (Station 3), with the maximum in Summer. Hawaii has a very weak variation. At Christmas Island the $\mathrm{SAO}$ is less regular, and indeed the clearest maxima are in April and November (Equinoctial months). The lowfrequency pattern is quite similar, but with mid-latitude stations demonstrating winter maxima in the SAO. The Hawaii $\mathrm{SAO}$ is stronger here, while the Christmas Island pattern is a stronger version of that at high frequencies. The variations of the NS components are very similar. It was argued in MMZ that, due to the stronger zonal winds, GW propagating in all but purely NS directions would experience filtering and doppler shifting due to their components of the EW winds.

Finally in Fig. 15 we show the contours of mean speeds of the background winds for the EW and NS directions. For the mid-latitudes (Yamagawa to Troms $\varnothing$ ) these EW contours follow the spectral-density contours in general form very well. Remembering that these sites demonstrated generally positive slopes for the spectral densities versus speeds (Figs. 2, 3 , and 4) and that solstitial months with higher mean speeds will have more spectra taken under high speed conditions, this is not surprising. Two other considerations: London had positive slopes for both GW bands (Figs. 2 and 3), which is consistent with the two strong summer contour-peaks at high and low frequencies in Fig. 14; and Troms $\varnothing$, which has stronger spectral peaks in summer (Fig. 14) than perhaps expected from the wind contour plots (Fig. 15), is a likely candidate for $\mathrm{GW}$ sources dominating the seasonal variations. This was an earlier conclusion in MMZ.

At the lower latitudes, the seasonal variations of the mean speeds is much less, as indeed are those of the spectral densities. In addition, these months demonstrated negative spectral density versus speed slopes (Figs. 6, 7, and 8, Table 1), which would further weaken the positive correlation between Figs. 14 and 15. However note the spring month of April at Christmas Island. Here the wind speed increases as does the spectral density. It was mentioned earlier (Subsection 4.2) that at this height and time a positive slope existed for the spectral density-speed plot. 
$\operatorname{Max}=\mathrm{X}$
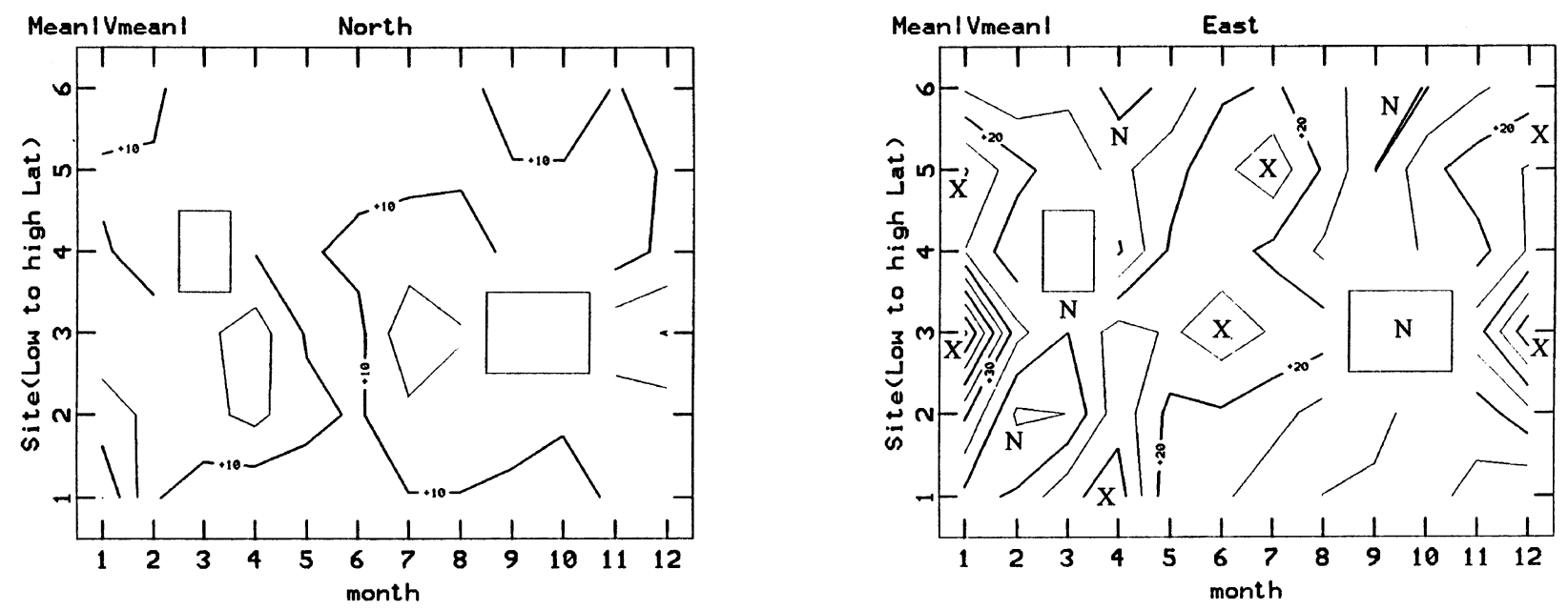

Fig. 15. Complementary to Fig. 11: contours of mean speeds $\left(\mathrm{m} \mathrm{s}^{-1}\right)$ for EW and NS components. The contours are $5 \mathrm{~m} \mathrm{~s}{ }^{-1}$.

The variation of NS speeds in Fig. 12 is relatively small, and does not have a obvious effect upon the spectral-density contours.

\section{Summary and Discussion}

There has already been quite considerable discussion of each theme in this paper at the end of each section. At this point a modest summary and discussion seems appropriate.

The focus of this paper has been to explore some patterns in the behaviour of spectra, the direction of predominant $\mathrm{GW}$ propagation, and GW-wind interactions, which had emerged from a previous study of MFR winds and waves data. This had used radars in the Canadian Prairies (3) and at Troms $\varnothing$. Here radars from Troms $\varnothing$, Saskatoon, London and Urbana, Yamagawa, Hawaii and Christmas Island have been used.

The frequency spectra (10 min.-10.7 hrs.) for the height layer $76-88 \mathrm{~km}$ and for radars from Troms $\varnothing$ to Urbana showed slopes of near $-5 / 3$ for winter months, but slopes nearer to -1 for higher frequencies ( $\tau<2$ hrs.) in summer and neighbouring equinoctial months. For the remaining lower latitudes (Yamagawa to Christmas Island) all months had more shallow slopes at the higher frequencies (Fig. 1). This could have been due to an enhanced noise-floor at the higher frequencies, but the accepted-data from all radars were of rather similar quality (based upon common analysis), so this is not considered very likely.

The earlier study had shown a dependence of spectral densities, especially at high frequencies, upon the mean wind speed for the observed interval (10.7 hrs.). This was here explored in a more organized fashion for all locations, by plotting spectral densities (two GW bands 10-100 min., 1$6 \mathrm{hrs}$.) for each spectrum versus mean wind speed. The resulting scatter plots were quite distinctive for high $/ \mathrm{mid}$ and low-latitudes. From Troms $\emptyset$ to Yamagawa the slopes were quite strongly and significantly positive at high frequencies (higher densities for larger mean speeds), and (apart from London) generally (if sometimes weakly) negative at low frequencies (Figs. 2, 3, and 4, and Table 1). For the low latitudes of Hawaii and Christmas Island, the slopes for both bands were negative, often strongly and significantly (Figs. 6, 7, and 8, and Table 1). A new analysis, based upon the correlation of the hourly mean wind and its standarddeviation over 10 days, as a function of azimuthal angle, was used to then infer GW (10- to 150 -min. periods) propagation directions. For the higher latitudes having positive slopes (spectral density vs. speed) at higher frequencies the propagation directions were anti-parallel to the mean winds (over 10 days) in the mesopause region $(76-82 \mathrm{~km}$ ), consistent with these waves being involved, via momentum deposition, with the closure of the solstitial jets (Fig. 5). The results from these two analysis methods are consistent with saturating waves whose perturbation speeds $\mathrm{v}^{\prime}$ vary as (cv), the GW intrinsic phase speeds. At the lower latitudes, which displayed negative slopes of spectral densities versus mean speeds, GW directions were inferred to be parallel to the mean winds and westward for much of the year; again these were internally consistent (Figs. 6, 7, and 9) and suggestive of unique low/equatorial-latitude interactions. GW saturation processes could be involved here; but also nonsaturation as decreasing westward winds would allow more waves to penetrate the region (Subsection 4.2). These findings are consistent with low latitude EW background winds measured by UARS, and related SAO studies. These will be explored, along with the possible role of the QBO, in other more detailed regional studies.

The perturbation ovals (Figs. 10, 11, 12, and 13) of the wind variances were used to demonstrate seasonal variations in GW variances (see also Fig. 14), and polarization (through major axis orientations). From Troms $\emptyset$ to Yamagawa, and for the 10-100 min. band, there was a clear SAO; the major axes orientations were all more zonal than for Saskatoon, with the NE-SW quadrant being favoured. At low latitudes the SAO was weak, a spring maximum existed, and directions were NW-SE (Hawaii) and meridional (Christmas Island). The 
ovals for the 1.5-6 hrs. band demonstrated a weaker SAO, and more variation with latitude and season in their polarization/orientation. This is consistent with the conclusion reached earlier by Manson et al. (1997), that these ovals are less dependent upon the mean winds at mesospheric heights and more dependent upon GW sources, and upon filtering below $76 \mathrm{~km}$ altitudes.

This has been a preliminary assessment of GW activity and characteristics as seen by the MF radars from Troms $\varnothing$ $\left(70^{\circ} \mathrm{N}\right)$ to Christmas Island $\left(2^{\circ} \mathrm{N}\right)$. Future work will be upon focused studies e.g. at tropical latitudes, paying attention to the QBO and specific oscillations such as the Kelvin Wave; and upon synergistic assimilative studies using GCM, and dedicated global ray tracing initiatives.

Acknowledgments. The scientists gratefully acknowledge grants from their national agencies: NSERC, Canada; NSF, USA; ARC, Australia. The first authors (Manson, Meek) also acknowledge support from the University of Saskatchewan, and the Institute of Space and Atmospheric Studies.

\section{References}

Cervara, M. A. and I. M. Reid, Comparison of simultaneous wind measurements using colocated VHF meteor radar and MF space antenna radar systems, Radio Sci., 30, 1245-1261, 1995.

Eckermann, S. D. and C. J. Marks, An idealized ray model of gravity wavetidal interactions, J. Geophys. Res., 101, 21,195-21,212, 1996.

Fritts, D. C., A review of gravity wave saturation processes, effects, and variability in the middle atmosphere, Pure Appl. Geophys., 130, 343371,1989

Fritts, D. C. and T. E. VanZandt, Effects of Doppler shifting on the frequency spectra of atmospehric gravity waves, J. Geophys. Res., 92, 9723-9732, 1987.

Fritts, D. C. and D.-Y. Wang. Doppler shifting effects on frequency spectra of atmospheric gravity waves, J. Atmos. Sci., 48, 1535-1544, 1991.

Gardner, C. S. and M. J. Taylor, Observational limits for lidar, radar, and airglow imager measurements of gravity wave parameters, J. Geophys. Res., 103, 6427-6430, 1998.

Gavrilov, N. M., A. H. Manson, and C. E. Meek, Climatological monthly characteristics of middle atmosphere gravity waves (10 min.-10 hrs.) during 1979-1993 at Saskatoon, Ann. Geophysicae, 13, 285-295, 1995.

Isler, J. R. and D. C. Fritts, Gravity wave variability and interaction with lower-frequency motions in the mesophere and lower thermosphere over Hawaii, J. Atmos. Sci., 53, 37-48, 1996.

Manson, A. H. Gravity wave horizontal and vertical wavelengths: An update of Measurements in the mesopause region ( 80-100 km), J. Atmos. Sci., 47, 2765-2773, 1990.

Manson, A. H. and C. E. Meek, Gravity wave propagation characteristics (60-120 km) as Determined by the Saskatoon MF Radar (Gravnet) system: $1983-85$ at $52^{\circ} \mathrm{N}, 107^{\circ} \mathrm{W}, \mathrm{J}$. Atmos. Sci., 45, 931-946, 1988.

Manson, A. H. and C. E. Meek, Characteristics of gravity waves (10 min.$6 \mathrm{hrs}$. ) at Saskatoon $\left(52^{\circ} \mathrm{N}, 107^{\circ} \mathrm{W}\right)$ : observations by the phase coherent medium frequency radar, J. Geophys. Res., D98, 20,357-20,367, 1993.

Manson, A. H., F. Yi, and C. E. Meek, Comparisons between instantaneous wind measurements made at Saskatoon $\left(52^{\circ} \mathrm{N}, 107^{\circ} \mathrm{W}\right)$ using the colocated medium frequency radars and Fabry-Perot interferometer instruments: Climatologies (1988-1992) and case studies, J. Geophys. Res., 101(D23), 29,553-29,563, 1996.
Manson, A. H., C. E. Meek, and Q. Zhan, Gravity wave spectra and direction statistics for the mesophere as observed by MF radars in the Canadian Prairies $\left(49^{\circ} \mathrm{N}-52^{\circ} \mathrm{N}\right)$ and at Troms $\emptyset\left(69^{\circ} \mathrm{N}\right)$, J. Atmos. Sol.-Terr. Phys., 59, 993-1009, 1997.

Manson, A. H., C. E. Meek, J. Qian, and C. S. Gardner, Spectra of gravity wave density and wind perturbations observed during Arctic Noctilucent Cloud (ANLC-93) campaign over the Canadian Prairies: Synergistic airborne Na lidar and MF radar observations, J. Geophys. Res., 103, 6455-6465, 1998a.

Manson, A. H., C. E. Meek, and G. E. Hall, Correlations of gravity waves and tides in the mesopause over Saskatoon, J. Atmos. Sol.-Terr. Phys., 60, 1089-1107, 1998b.

McLandress, C., On the importance of gravity waves in the middle atmosphere and their parameterization in general circulation models, J. Atmos. Sol.-Terr. Phys., 60, 1357-1384, 1998.

Medvedev, A. S., G. P. Klaassen, and S. R. Beagley, On the role of an anisotropic gravity wave spectrum in maintaining the circulation of the middle atmosphere, Geophys. Res. Lett., 25, 509-512, 1998.

Meek, C. E., An efficient method for analyzing ionospheric drifts data, $J$. Atmos. Terr. Phys., 42, 835-839, 1980.

Meek, C. E., I. M. Reid, and A. H. Manson, Observations of mesopheric wind velocities. 2. Cross-sections of power spectral density for 48-8 hours, 8-1 hours, 1 hour-10 min. over $60-110 \mathrm{~km}$ for 1981, Radio Sci., 20, 1383-1402, 1985.

Meek, C. E., A. H. Manson, M. D. Burrage, G. Garbe, and L. L. Cogger, Comparisons between Canadian prairie MF radars, FPI (green and $\mathrm{OH}$ lines) and UARS HRDI systems, Ann. Geophysicae, 15, 1099-1110, 1997.

Nakamura, T., T. Tsuda, S. Fukao, S. Kato, A. H. Manson, and C. E. Meek, Comparative observations of short-period gravity waves (10-100 min.) in the mesosphere in 1989 by Saskatoon MF radar $\left(52^{\circ} \mathrm{N}\right)$, Canada and the MU radar $\left(35^{\circ} \mathrm{N}\right)$, Radio Sci., 28, 729-746, 1993.

Nakamura, T., T. Tsuda, S. Fukao, A. H. Manson, C. E. Meek, R. A. Vincent, and I. M. Reid, Mesopheric gravity waves at Saskatoon $\left(52^{\circ} \mathrm{N}\right)$, Kyoto $\left(35^{\circ} \mathrm{N}\right)$ and Adelaide $\left(35^{\circ} \mathrm{S}\right)$, J. Geophys. Res., 101, 7005-7012, 1996.

Rastogi, P. K., E. Kudeki, and F. Sürücü, Distortion of gravity wave spectra of horizontal winds measured in atmospheric radar experiments, Radio Sci., 31, 105-118, 1996.

Shepherd, T. G., The Canadian MAM project, CMOS Bulletin, 23, 3-10, 1995.

Thayaparan, T., W. K. Hocking, and J. MacDougall, Middle atmospheric winds and tides over London, Canada $\left(43^{\circ} \mathrm{N}, 81^{\circ} \mathrm{W}\right)$ during $1992-1993$, Radio Sci., 30, 1293-1309, 1995.

Thorsen, D., S. J. Franke, Climatology of mesopheric gravity wave activity over Urbana, Illinois $\left(40^{\circ} \mathrm{N}, 88^{\circ} \mathrm{W}\right)$, J. Geophys. Res., 103, 3767-3780, 1998.

Vincent, R. A. and D. C. Fritts, A climatology of gravity wave motions in the mesopause region at Adelaide, Australia, J. Atmos. Sci., 44, 748-760, 1987.

Wiens, R. H., D. Y. Wang, R. N. Peterson, and G. G. Shepherd, Statistics of gravity waves seen in $\mathrm{O}_{2}$ nightglow over Bear Lake Observatory, $J$. Geophys. Res., 102, 7319-7329, 1997.

Zhan, Q., A. H. Manson, and C. E. Meek, The impact of gaps and spectral methods on the spectral slope of the middle atmospheric wind, J. Atmos Terr. Phys., 58, 1329-1336, 1996.

Zhong, L., A. H. Manson, L. J. Sonmor, and C. E. Meek, Gravity wave exclusion circles in background flows modulated by the semi-diurnal tide, Ann. Geophysicae, 14, 557-565, 1996.

A. H. Manson (e-mail: manson@dansas.usask.ca), C. E. Meek, C. Hall, W. K. Hocking, J. MacDougall, S. Franke, K. Igarashi, D. Riggin, D. C. Fritts, and R. A. Vincent 